University of Louisville

ThinkIR: The University of Louisville's Institutional Repository

Electronic Theses and Dissertations

$12-2018$

\title{
Effect of grape components on periodontal disease.
}

Juili Subodh Shivde

University of Louisville

Follow this and additional works at: https://ir.library.louisville.edu/etd

Part of the Dental Public Health and Education Commons, Oral Biology and Oral Pathology Commons, and the Periodontics and Periodontology Commons

\section{Recommended Citation}

Shivde, Juili Subodh, "Effect of grape components on periodontal disease." (2018). Electronic Theses and Dissertations. Paper 3094.

https://doi.org/10.18297/etd/3094

This Master's Thesis is brought to you for free and open access by ThinkIR: The University of Louisville's Institutional Repository. It has been accepted for inclusion in Electronic Theses and Dissertations by an authorized administrator of ThinkIR: The University of Louisville's Institutional Repository. This title appears here courtesy of the author, who has retained all other copyrights. For more information, please contact thinkir@louisville.edu. 


\title{
EFFECT OF GRAPE COMPONENTS ON PERIODONTAL DISEASE
}

\author{
By
}

Juili Subodh Shivde

B.D.S., Maharashtra University of Health Sciences, 2015

\author{
A Thesis \\ Submitted to the Faculty of the \\ School of Dentistry of the University of Louisville \\ in Partial Fulfillment of the Requirements \\ for the Degree of
}

\author{
Master of Science \\ in Oral Biology
}
Department of Oral Immunology and Infectious Diseases
University of Louisville School of Dentistry
Louisville, Kentucky

December 2018 
Copyright 2018 by Juili Subodh Shivde

All rights reserved 



\title{
EFFECT OF GRAPE COMPONENTS ON PERIODONTAL DISEASE
}

\author{
By
}

Juili Subodh Shivde

B.D.S., Maharashtra University of Health Sciences, 2015

A Thesis Approved on

November 20, 2018

by the following Thesis Committee:

Dr. Shuang Liang (Thesis Director)

Dr. David Scott (Committee member)

Dr. Lisa Sandell (Committee member) 


\section{DEDICATION}

This thesis is dedicated to my parents

Dr. Subodh Ratnakar Shivde

and

Dr. Bhagyashree Subodh Shivde

For giving me this beautiful life and never-ending opportunities to chase my dreams. 


\section{ACKNOWLEGEMENTS}

I am extremely grateful to my mentor Dr. Shuang Liang for giving me this wonderful research opportunity, having been a constant support and guidance throughout the duration of my master's program. I would like to thank my thesis committee members, Dr. David Scott and Dr. Lisa Sandell for their continued guidance and encouragement. I would like to thank my lab team, especially Dr. Wei Zhou and Jian Xin Zhu for always being around if I needed any help or assistance during my research procedures. I would also like to acknowledge Satya, Aislinn, Dr. Li and Dr. Xingyu Duan. Lastly, thank you to the rest of my family members, brother Sujoy and friends. 


\section{ABSTRACT \\ EFFECT OF GRAPE COMPONENTS ON PERIODONTAL DISEASE \\ Juili Shivde}

November 20, 2018

Background: Half of the adult American population (47\%) are victims of periodontitis, a chronic inflammatory disease which leads to destruction of the tissues supporting the tooth. Periodontitis is initiated by periodontal pathogens and caused by excessive or prolonged host mediated inflammation. Porphyromonas gingivalis is one important agent implicated in the etiopathogenesis of chronic periodontitis. Pro-inflammatory cytokines induced by periodontal pathogens can cause alveolar bone loss and periodontitis. Bone loss is caused by the imbalance of bone formation and bone resorption. Osteoclasts are major cells that cause bone resorption. Moreover, periodontal inflammation also leads to bone resorption. Grapes are rich in several components like catechin and proanthocyanidins, which possess extensive biologic properties including inhibitory effects on oral bacteria and the ability to suppress inflammation. Grape components may intensely inhibit osteoclastogenesis by suppressing osteoclast differentiation and thus may be beneficial in anti-inflammatory treatment accompanying bone destruction. Grapes may thus prove as a promising natural therapeutic agent for periodontitis therapy. They may exhibit their anti-inflammatory and immunomodulatory properties by suppressing the activation of NF- $\kappa$ B signal transduction pathways (Lee, Kim et al. 2017) (Chu, Tang et al. 2016). The focus of this study was to determine the effects of grape components on 
bacterial growth, inflammation, and osteoclastogenesis in vitro and gingival inflammation and bone loss in vivo.

Hypothesis: We hypothesize that grape powder extract will inhibit $P$. gingivalis growth, suppress pro-inflammatory cytokines and inhibit osteoclastogenesis in vitro. We also hypothesize that grape powder inhibits gingival inflammation and prevents bone loss in a murine model.

Methods: In vitro - the effect of grape powder extract on bacterial growth was tested by inoculating $P$. gingivalis into $1.5 \mathrm{ml}$ microcentrifuge tubes containing different concentrations $(0.0625,0.125,0.5 \mu \mathrm{g} / \mathrm{ml})$ of grape powder extract and incubating the tubes at $37^{\circ} \mathrm{C}$ for $24 \mathrm{~h}$. Controls included no grape powder treatment. The bacterial number was determined by plating on blood agar for CFU. $10^{5}$ Murine RAW 264.7 cells were treated with grape powder extract $(50,100,200 \mu \mathrm{g} / \mathrm{ml})$ or no grape powder extract and stimulated with $1 \mu \mathrm{g} / \mathrm{ml} P$. gingivalis LPS overnight and tested for the expression of IL-6 by ELISA. Similarly, $10^{5}$ THP1-Blue cells ${ }^{\mathrm{TM}}$ were treated with grape powder extract $(50,100,200 \mu \mathrm{g} / \mathrm{ml})$ or no grape powder extract, stimulated with $10 \mu \mathrm{g} / \mathrm{ml} P$. gingivalis LPS overnight. Activity of NF- $\mathrm{BB}$-inducible alkaline phosphatase in THP1-Blue cells ${ }^{\mathrm{TM}}$ was determined by colorimetric activation. $10^{3}$ RAW 264.7 cells were stimulated with $100 \mathrm{ng} / \mathrm{ml}$ RANKL and treated with $200 \mu \mathrm{g} / \mathrm{ml}$ grape powder extract. The cells with no grape powder extract treatment were used as controls. Seven days later, the cultures were fixed and stained with TRAP for 15 mins, an osteoclast marker and the number of TRAP positive cells were counted microscopically. 
In vivo- Grape powder was tested in a 7-day murine ligature-induced periodontitis model where mice received a ligation around the second molar and also a baker model, where $P$. gingivalis was orally infected and mice were kept for 2 months. The mice consumed a grape powder or no grape powder diet. Maxillary gingival tissue was tested for mRNA expression of pro-inflammatory and anti-inflammatory cytokines by Quantitative realtime PCR in the ligature model. Alveolar bone loss was determined by measuring the CEJ-ABC distance in the baker model. The statistical analysis used was a two-tailed $t$ test. (GraphPad Prism Software, San Diego, CA, USA). Differences were considered statistically significant at a $P$ value of $<0.05$.

Results: There was a decrease in the number of oral bacteria (CFU) with increasing concentration of grape powder extract. Thus, grape powder extract inhibited $P$. gingivalis growth. RAW 264.7 cells stimulated with $P$. gingivalis only showed maximum levels of IL-6 production. However, in the cells that received grape powder extract, a decrease in the amount of IL-6 was noted. THP1-Blue cells ${ }^{\mathrm{TM}}$ stimulated with $P$. gingivalis LPS and

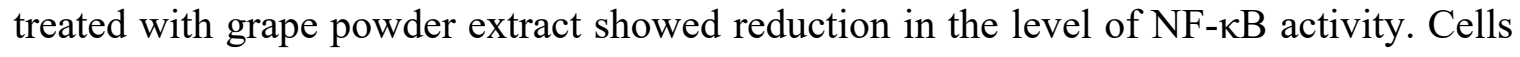
without RANKL stimulation and grape powder extract treatment showed no formation of TRAP-positive cells. Cells treated with grape powder extract showed a significant reduction in the number of TRAP positive cells. Thus, grape powder extract inhibited $P$. gingivalis growth, osteoclastogenesis and $P$. gingivalis-induced pro-inflammatory cytokine production in vitro. There was a reduction in the levels of pro-inflammatory cytokines IL- 6 and TNF- $\alpha$ after treatment with grape powder in ligature model mice. However, there were no significant changes in the levels of IL-17, IL-1 $\beta$, IL-10 and 
TGF- $\beta$. CEJ-ABC distance was also reduced which indicated bone loss in the baker model. Overall, grape powder reduced gingival inflammation and bone loss in murine models.

Conclusion and practical implications: Grape components or grape consumption can be beneficial in the prevention or treatment of periodontal disease. Grape components can be useful for further development as a potential and safe therapeutic agent in periodontal disease treatment.

Keywords: Grape components, NF- $\kappa$ B pathway, periodontal diseases, osteoclastogenesis, inflammation, alveolar bone loss, P. gingivalis 
TABLE OF CONTENTS

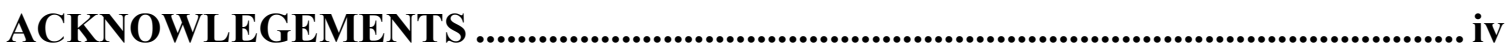

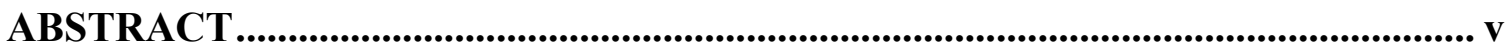

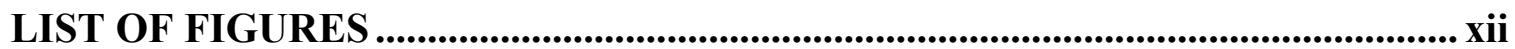

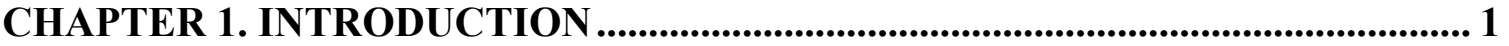

1.1. CHRONIC PERIODONTITIS .................................................................. 1

1.2. PATHOGENESIS OF CHRONIC PERIODONTITIS .................................. 3

1.2.1. PERIODONTAL DISEASE AND ORAL PATHOGENS ........................... 3

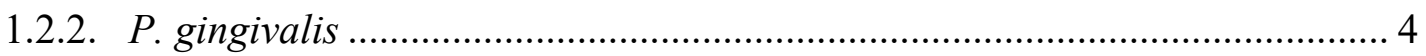

1.3. PERIODONTAL DISEASE AND INFLAMMATION ............................. 6

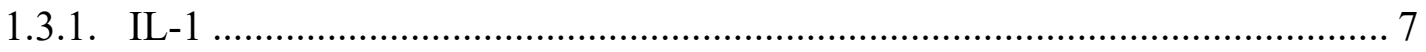

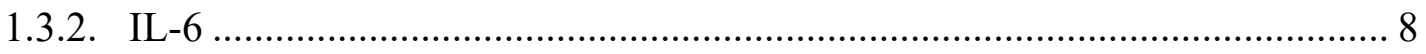

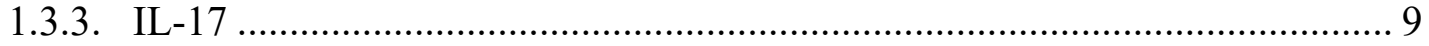

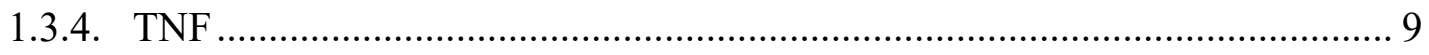

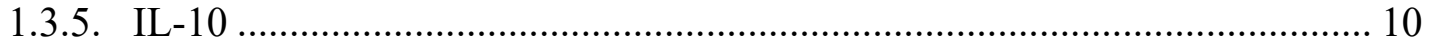

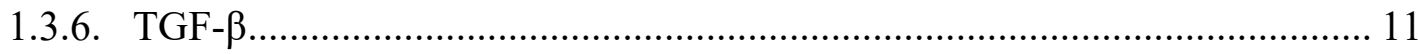

1.4. PERIODONTAL DISEASE AND BONE LOSS .................................... 11 
1.5. NF-кB SIGNALING PATHWAY AND PERIODONTAL DISEASE...... 13

1.6. PERIODONTAL PATHOGENS, $P$. gingivalis AND NF-кB SIGNALING

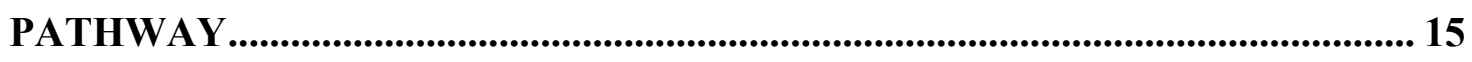

1.7. NF-кB SIGNALING PATHWAY AND $P$. gingivalis ............................. 16

1.8. NF-кB, OSTEOCLASTOGENESIS, RANKL/RANK/OPG Pathway ...... 17

1.9. FRUITS IN HEALTH ........................................................................ 18

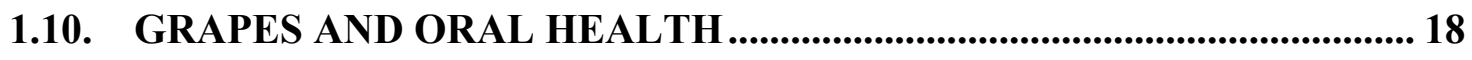

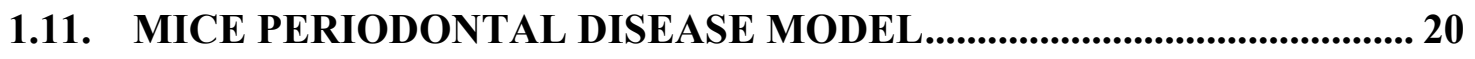

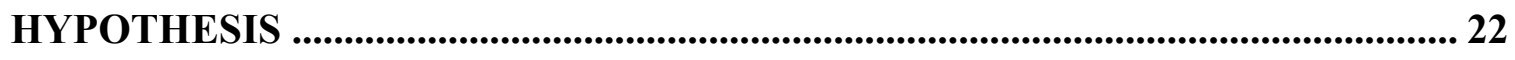

CHAPTER 2. MATERIALS AND METHODS................................................. 23

2.1. In-vitro EXPERIMENTS ........................................................................... 23

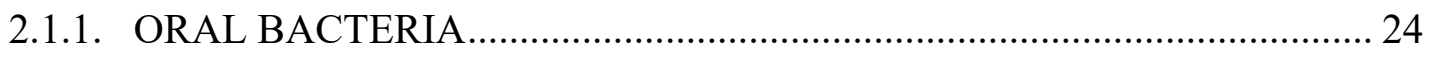

2.1.2. PRO-INFLAMMATORY CYTOKINE EXPRESSION …....................... 25

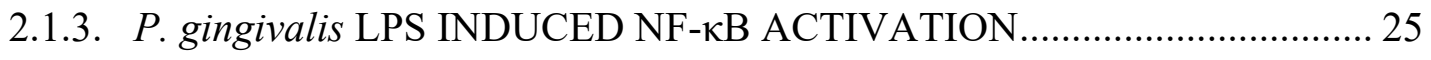

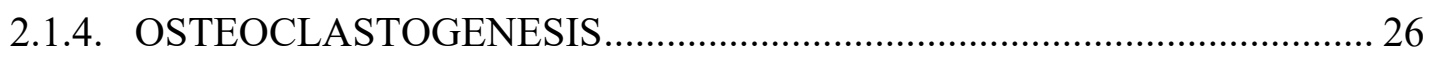

2.2. In-vivo EXPERIMENTS ........................................................................ 26

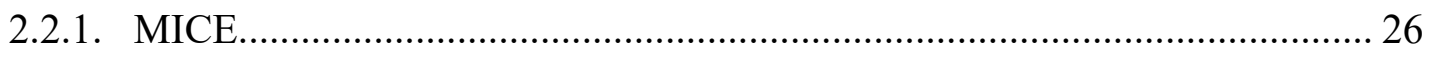

2.2.2. MURINE LIGATURE INDUCED PERIODONTITIS MODEL................ 27

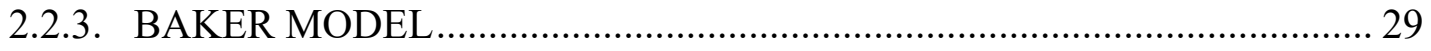

2.2.4. GINGIVAL TISSUE HARVEST IN LIGATURE MODEL...................... 31 
2.2.5. HARVEST OF MAXILLARY JAW BONE AND ALVEOLAR BONE

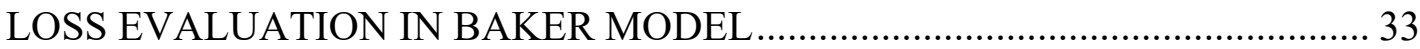

2.3. STATISTICAL ANALYSIS ............................................................ 34

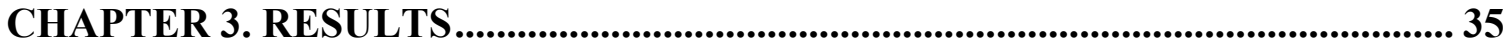

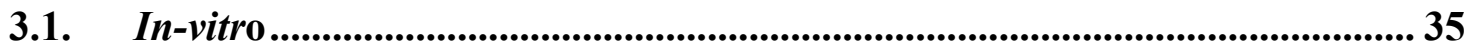

3.1.1. GRAPE POWDER EXTRACT INHIBITS $P$. gingivalis GROWTH. ......... 35

3.1.2. GRAPE POWDER EXTRACT INHIBITS $P$. gingivalis- LPS INDUCED PRO-INFLAMMATORY CYTOKINE PRODUCTION ................................... 37

3.1.3. GRAPE POWDER EXTRACT INHIBITS $P$. gingivalis LPS-INDUCED

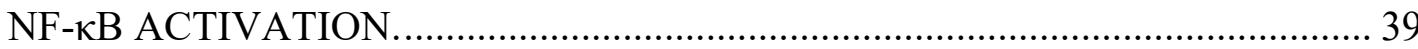

3.1.4. GRAPE POWDER EXTRACT INHIBITS RANKL-INDUCED

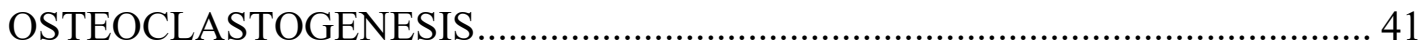

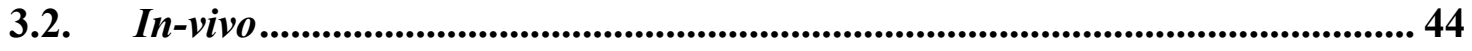

3.2.1. GRAPE POWDER TREATMENT DOWNREGULATES THE EXPRESSION OF PRO-INFLAMMATORY CYTOKINES IL-6 AND TNF- $\alpha$.... 44 3.2.2...... GRAPE POWDER INHIBITS ALVEOLAR BONE LOSS IN A MURINE

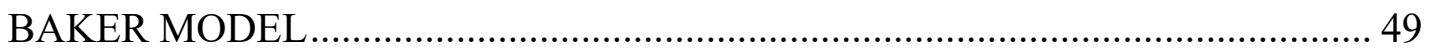

CHAPTER 4. DISCUSSION .................................................................................... 52

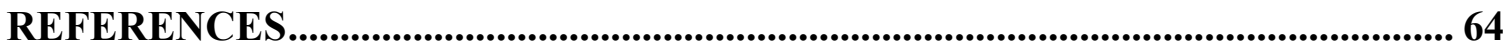

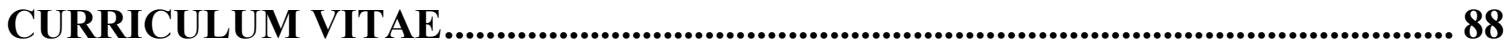




\section{LIST OF FIGURES}

Figure 1. 20x microscopic image of Tartrate resistant acid phosphatase positive (TRAP) osteoclasts characterized by large round appearance and presence of multiple nuclei in the cytoplasm surrounded by RAW 264.7 monocytes.............................................. 12

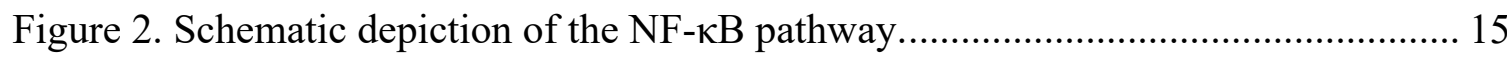

Figure 3. Schematic depiction of the protocol for periodontitis induction in vivo using

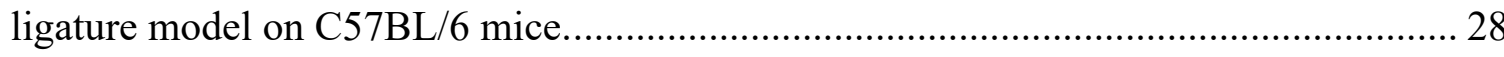

Figure 4. Schematic depiction of the protocol for periodontitis induction in vivo using

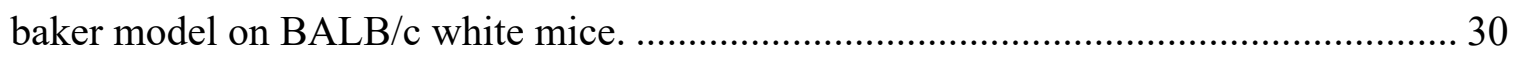
Figure 5. Schematic depiction of mice maxilla showing molar and incisor teeth and

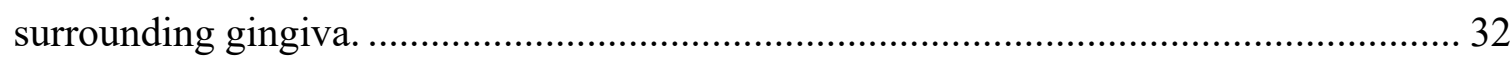
Figure 6. Microscopic picture of mice maxillary teeth showing the seven sites of measurement from the $\mathrm{CEJ}$ to $\mathrm{ABC}$ (depicted by black arrows) on the right buccal side after staining with methylene blue for visualization of the CEJ (Baker model).............. 34 Figure 7. Graphical comparison of $P$. gingivalis growth after treatment with different concentrations of grape powder extract.

Figure 8. Comparison of different concentrations of grape powder extract and DMSO on P. gingivalis-LPS induced pro-inflammatory cytokine IL-6 production in RAW 264.7 cells. 38

Figure 9. Comparison of level of $P$. gingivalis LPS-induced NF- $\kappa \mathrm{B}$ activation at different concentrations of grape powder extract in THP1-Blue cells ${ }^{\mathrm{TM}}$. 40 
Figure 10. Comparison of number of osteoclasts produced in RAW 264.7 cells with RANKL at 0 and $200 \mu \mathrm{g} / \mathrm{ml}$ of grape powder extract and RAW 264.7 cells without RANKL and grape powder.

Figure 11.20x microscopic images showing comparison of number of TRAP positive osteoclasts produced in a 96 well plate in 3 different conditions

Figure 12. Comparison of gingival mRNA expression of IL-6 and TNF- $\alpha$ relative to internal control gene GAPDH in four different groups of mice.

Figure 13. Comparison of gingival mRNA expression of IL-17 and IL-1 $\beta$ relative to internal control gene GAPDH in four different groups of mice

Figure 14. Comparison of gingival mRNA expression of anti-inflammatory cytokines TGF- $\beta$ and IL-10 relative to internal control gene GAPDH in four different groups of mice.

Figure 15. Comparison of CEJ-ABC distance and bone loss between different groups of mice 50 


\section{CHAPTER 1. INTRODUCTION}

\subsection{CHRONIC PERIODONTITIS}

Epidemiological data in the USA derived from the National Health and Nutrition Examination Survey (NHANES) stated that $47 \%$ of adults had chronic periodontitis which represented 64.7 million of the adult American population. $8.9 \%$ of this lot had severe periodontitis. (Eke, Dye et al. 2015). Some other studies reported that periodontal disease affected $70 \%$ of the adult population aged 65 years and older (Papapanou, 2012). According to $\mathrm{WHO}, 10-15 \%$ of the population worldwide were victims of periodontitis (Peterson and Ogawa, 2005). The prevailing paradigm reports that 538 million people suffer from severe periodontal disease; and 276 million people worldwide exhibit total tooth loss. The figures are expected to be on the rise as population grows and ages (Kassebaum, Smith et al. 2017). Ironically, the treatment for periodontitis is very expensive and majority of the victims fall under the low-income groups. They thus refrain from seeking proper treatment (Petersen, Bourgeois et al. 2005). As of 2010, it was reported that the cost of treatment for oral conditions including periodontitis were estimated at US\$298 billion worldwide, which accounted for around $4.6 \%$ of the total money spent on global health (Kassebaum, Smith et al. 2017).

Periodontitis is a microbial biofilm-induced, host-mediated inflammatory disease that leads to clinical attachment loss (CAL). This attachment loss can be identified clinically by a circumferential evaluation of the erupted teeth with the aid of a standardized 
instrument called the periodontal probe using cemento-enamel junction (CEJ) as a landmark (Tonetti, Greenwell et al. 2018). Although the microbial biofilm is required but not sufficient to cause disease, the host inflammatory response to the microbial challenge is the key to periodontal destruction (Hajishengallis and Lamont 2012). Periodontitis may impact systemic health (Kinane, Stathopoulou et al. 2017). The framework for staging and grading of periodontitis has been classified as Stage 1 - Initial periodontitis, Stage 2 - Moderate periodontitis, Stage 3 - Severe periodontitis with potential for additional tooth loss, Stage 4 - Advanced periodontitis with extensive tooth loss and potential for loss of dentition. This classification is based upon the disease severity and complexity of management (Tonetti, Greenwell et al. 2018).

Periodontitis is one of the most common inflammatory diseases encountered in the oral cavity (Zhou, Su et al. 2018). In 1998, the etiology of periodontitis was fueled by one theory that specific organisms like Porphyromonas gingivalis, Treponema Denticola and Tanerella Forsythia, popularly known as the "red complex", were responsible for disease progression. The complexes were established based on the results of multiple cluster and community ordination analysis using DNA probes with the red complex exhibiting a striking relation to periodontal pocket depth and bleeding on probing. (Socransky, Haffajee et al. 1998). However, recently the etiology has shifted in favor of the polymicrobial synergy and dysbiosis (the 'PSD model') (Hajishengallis and Lamont 2012). Dysbiosis or imbalance in the ecosystem of microorganisms further leads to changes in the host-microbe crosstalk resulting in destructive inflammation and bone loss typical of periodontal disease (Abusleme, Dupuy et al. 2013). Apart from being a major factor causing loss of teeth, severe periodontitis has been linked to several systemic 
diseases like atherosclerosis, diabetes, rheumatoid arthritis and adverse pregnancy outcomes like low birth weight (Kinane, Stathopoulou et al. 2017)(Madianos, 2013)(Khader, Dauod et al. 2006). Periodontal disease may expedite the progression of these diseases due to increased overall inflammatory load on the body or pathogen invasion into the circulation (Khader, Dauod et al. 2006).

\subsection{PATHOGENESIS OF CHRONIC PERIODONTITIS}

\subsubsection{PERIODONTAL DISEASE AND ORAL PATHOGENS}

Microbes were discovered as early as the 1700's by renowned scientist Antonie van Leeuwenhoek (Gordon and Klaenhammer 2011). The microorganisms found in the oral cavity have been termed as oral microflora, oral microbiota or oral microbiome which are estimated to be around 600 different species with distinct subspecies (Dewhirst, Chen et al. 2010). A balance between the resident microbiota and host immune response maintains a state of homeostasis. However, imbalance between the same contributes to oral diseases like caries or periodontal disease (Gao, Xu et al. 2018). Researchers believe that some of the most prevalent periodontal pathogens encountered in the oral cavity are Aggregatibacter actinomycetemcomitans, Fusobacterium nucleatum, Tannerella forsythia (formerly Bacteroides forsythus), Porphyromonas gingivalis, Prevotella intermedia and Treponema denticola (Aruni, Dou et al. 2015). The oral bacterial biofilm was first described by James Eon Wiliams in 1897 as a gel-like mass of bacteria adhering to the tooth surface (Cassai, Galvan et al. 2003). Periodontitis is one good example of a biofilm-associated dental infection (Bergstrom 2006). The etiology of this biofilminduced disease has been associated with several theories - keystone pathogen, red 
complex, specific and non-specific microorganisms, polymicrobial synergy and dysbiosis to name a few (Hajishengallis 2014).

\subsubsection{P. gingivalis}

P. gingivalis is a Gram-negative, anaerobic, rod-shaped bacteria forming black colonies on blood agar. It has been identified by researchers as one of the causative factors in the pathogenesis and the severity of periodontal disease (Geng, Liu et al. 2017). Although reported as most prevalent by some studies in animal models, the keystone pathogen theory postulates that $P$. gingivalis in low abundance induces chronic periodontitis by remodeling the commensal bacterial community to promote a state of dysbiosis leading to disease. In other words, this bacteria in relatively low numbers could interfere with the organization of the existing symbiosis between the local oral bacteria which in turn effects the innate immune response (Olsen, Lambris et al. 2017). It thus might be implicated in the pathogenesis of periodontal disease since it was detected in $85.75 \%$ subgingival plaque of chronic periodontitis patients (How, Song et al. 2016). P. gingivalis is particularly of interest to researchers due to its easy method of culture and ability to alter genetic makeup (Hajishengallis and Lamont 2012).

P. gingivalis benefits from several companion species like Streptococcus gordonii in the sub gingival plaque on its path to tissue destruction. It can efficiently modify the host immune response and create an environment favorable to its continued persistence (Hajishengallis, Liang et al. 2011). Keystone pathogen P. gingivalis and accessory pathogen S. gordonii interact to form communities and subsequent colonization of dental plaque (Kuboniwa, Houser et al. 2017). Although the mechanistic of this interaction are 
not fully elucidated, it is believed that $P$. gingivalis binds to GAPDH and surface proteins on the surface of $S$. gordonii which ultimately favor the formation of $P$. gingivalis biofilms on the tooth surface (Maeda, Nagata et al. 2015).

P. gingivalis is known to produce a wide array of virulence factors that could cause tissue destruction on their own or through other mediators, with inflammation as an outcome (Hajishengallis and Lamont 2014). Virulence factors are integral molecules expressed by an organism at various stages of its life cycle with capacity to damage the host, namely enzymes, capsule, lipopolysaccharide, fimbriae etc. (How, Song et al. 2016).

Lipopolysaccharide (LPS) is a pathogen associated molecular pattern (PAMP) or more recently identified as microbe-associated molecular pattern (MAMP) (Newman, Sundelin et al. 2013) and also a major component of the gram-negative bacterial cell walls of periodontal pathogen $P$. gingivalis (Darveau, Arbabi et al. 2002). It mediates the host inflammatory response by stimulating Toll-like receptor 4 (TLR4) (Park and Lee 2013). Lipid A component of LPS present in its outermost membrane is responsible for its virulence properties. P. gingivalis LPS contains multiple forms of Lipid A (Darveau, Pham et al. 2004). The chemical structure of $P$. gingivalis Lipid A was determined to be a glucosamine beta-(1-6) disaccharide 1-monophosphate acylated by 3-hydroxy-15methylhexadecanoic acid and 3-hexadecanoyloxy-15-methylhexadecanoic acid at the 2and 2'-positions, respectively (Ogawa 1993). Host cells are highly specific and sensitive to Lipid A which contributes to the inflammatory response of gingival tissues, thereby creating a favorable environment for pathogens to sustain and ultimately cause periodontal disease progression (Herath, Darveau et al. 2013). It also comprises the outer leaflet of most other Gram-negative commensal bacteria like E.coli (Wang and Quinn 
2010). LPS exists as structurally different forms in different bacterial species depending on fatty acid acyl chain composition and charge which may elucidate the mechanism by which the host may recognize bacterial species. The variation of LPS in different strains of $P$. gingivalis has been identified, however the basis for this variation still remains controversial (Darveau, Arbabi et al. 2002). LPS has been chosen as our virulence factor of interest due its stable nature and easy availability commercially.

\subsection{PERIODONTAL DISEASE AND INFLAMMATION}

Roman scholar Celcus defines inflammation as a common physical condition in which some part of the body exhibits rubor (redness), calor (heat), dolor (pain) and swelling (tumor) (Ciaccia 2011). Recently, a fifth sign has also been defined which is function laesa (loss of function). Periodontal disease begins with gingivitis, which is a localized inflammatory response in the gingiva to harmful stimuli of oral bacteria. Ideally at this stage, elimination of the supra gingival and sub gingival plague by resorting to mechanical methods like scaling and root planning will allow the junctional epithelium (tissue that connects the tooth to the bone) to grow and restore tissue health. If left untreated, the gingivitis progresses to periodontitis. As suggested by the 2017 World Workshop, a patient is said to have periodontitis if clinically, there is interdental CAL identifiable at 2 or more than 2 non-adjacent teeth, OR buccal or oral CAL is $3 \mathrm{~mm}$ or greater with pocket formation greater than $3 \mathrm{~mm}$ and identifiable at 2 or more teeth. Also, the CAL may not have occurred as a result of any non-periodontal causes and is detectable clinically (Tonetti, Greenwell et al. 2018). Although the microbial biofilm is the prime initiator of periodontal disease, genetic and environmental factors play a major role in its sustenance (Kinane, Stathopoulou et al. 2017). 
Cytokines are small secreted proteins and regulators of host response to infection, immune response, inflammation and trauma. Pro-inflammatory cytokines released by activated macrophages up-regulate inflammatory reactions associated with tissue destruction and disease progression. In contrast, anti-inflammatory cytokines control the response of pro-inflammatory cytokines to attenuate the disease process (Zhang and An 2007).

Pro-inflammatory cytokines such as IL1- $\beta$, IL-6 and TNF- $\alpha$ promote the function of osteoclasts through activation of nuclear factor kappa-B ligand (RANKL) (Di Benedetto, Gigante et al. 2013) (Kato et al., 2014). These cytokines coincide with the loss of attachment and bone resorption critical to periodontal disease. The tissue destruction is simply the outcome of the immoderate production of these cytokines due to exaggerated host immune response (Graves and Cochran 2003).

Interleukins are a group of cytokines produced by one leukocyte but act at a leukocyte site different from their production (Zhang and An 2007). They have gained popularity lately due to the investigation regarding their role in periodontal disease. Here is a brief summary of pro-inflammatory cytokines implicated in the pathogenesis of periodontal disease:

\subsubsection{IL-1}

IL-1 has an impressive range of biological functions including the ability to control genes conducive to inflammation (Dinarello 1996). It exists as two subtypes IL- $1 \alpha$ and IL-1 $\beta$. Studies conducted on mice have shown that in the absence of IL-1 there is an exaggerated inflammatory response and higher chances of developing infection (Labow, Shuster et al. 
1997). Only recently, several researchers have demonstrated that IL-1 is produced in higher levels at periodontal disease sites. Injection of IL-1 in a murine model showed signs of inflammation and bone resorption classic of periodontal disease (Hanazawa, Nakada et al. 1985, Jandinski, Stashenko et al. 1991) (Kinane, Winstanley et al. 1992) (Koide, Suda et al. 1995). The cellular sources of IL-1 in periodontal disease include monocytes/macrophages, leukocytes, fibroblasts (gingival and periodontal ligament), epithelial cells and osteoblasts (Graves and Cochran 2003). It is also one amongst the most potent bone resorbing agents (Bertolini, Nedwin et al. 1986).

\subsubsection{IL-6}

IL-6 is a pro-inflammatory multifunctional cytokine produced by various cell types like B- lymphocytes, monocytes, macrophages, keratinocytes and fibroblasts (Irwin and Myrillas 1998). It is released in response to bacterial products like lipopolysaccharides or in conjunction with fellow cytokines IL-1 $\beta$ and TNF- $\alpha$ (Kishimoto 1989). IL-6 is a potent inducer of osteoclast formation and has been proven to cause bone resorption alone and in synergism with IL-1 $\beta$ when tested in a murine model (Ishimi, Miyaura et al. 1990). IL6 has been found in the Gingival Crevicular Fluid associated with periodontal disease sites which supports the theory that there is a correlation between concentration of IL-6 and level of periodontal disease. Due to its overall osteoclast-inducing nature, it is not surprising for IL-6 to be implicated in pathological bone conditions like Rheumatoid arthritis, Paget's disease and Gorham-stout disease (Irwin and Myrillas 1998). 


\subsubsection{IL-17}

IL-17 is a pro-inflammatory cytokine which derives its origin from rodent T cells (Gaffen 2008). It is produced by a family of specialized T helper cells (Th17) as an outcome of IL-23 stimulation. Until recently, the role of IL-17 has also been highlighted in innate as well as adaptive immunity. Several studies have reported a disputable role of IL-17 in protection and promotion of inflammatory diseases (Miossec, Korn et al. 2009). IL-17 is known for its ability to ward off bacterial invasion at various sites of infection thus safeguarding the defensive immune response (Jin and Dong 2013). We were interested in studying IL-17 to increase our knowledge on the possible role of IL-17 in the pathogenesis of periodontal diseases. This cytokine can promote inflammation, assist immune responses and stimulate bone resorption by osteoclastogenesis in association with receptor activator of NF-kappaB (RANK) and RANK ligand (RANKL) (Takahashi, Azuma et al. 2005) (Chabaud and Miossec 2001). IL-17 can accentuate the inflammatory response by working in synergy with other inflammatory cytokines like TNF- $\alpha$ and IL-1 $\beta$ (Chabaud, Fossiez et al. 1998) (Onishi and Gaffen 2010).

\subsubsection{TNF}

Tumor Necrosis Factor or TNF includes two protein subsets - TNF- $\alpha$, and TNF- $\beta$. Of these two TNF- $\alpha$ has been identified as a 'major inflammatory cytokine' for not only being a key player in periodontal tissue destruction but also exhibiting toxic response to the host tissue (Gokul, Faizuddin et al. 2012). It has been located in major abundance in the gingival crevicular fluid and serum (Garlet 2010, Di Benedetto, Gigante et al. 2013). The levels of TNF- $\alpha$ in the gingival crevicular fluid can be used as a good biochemical 
'marker' of periodontal disease (Gokul, Faizuddin et al. 2012). TNF- $\alpha$ promotes osteoclastogenesis in several inflammatory conditions like periodontitis, rheumatoid arthritis, orthopedic implant failures and peri-implantitis (Zhang, Heulsmann et al. 2001, Garlet 2010). It is also known to increase the response of fellow cytokines like IL-1 $\beta$ and IL-6 during inflammatory conditions (Garlet 2010, Di Benedetto, Gigante et al. 2013). Expression of inflammatory mediators, chemokines, matrix metalloproteinase are some of the mechanistic of TNF- $\alpha$ in periodontal disease in a synergistic relationship with IL-1 (Graves and Cochran 2003).

Anti-inflammatory cytokines are soluble or cell-surface molecules that reduce inflammation by directly antagonizing the function of pro-inflammatory cytokines. A few are summarized below:

\subsubsection{IL-10}

Interleukin 10 (IL-10) plays a protective role in inflammatory diseases by suppressing the host immune response to bacterial invasion thereby limiting damage to the host (Iyer and Cheng 2012). Major sources of IL-10 include T helper cells, monocytes, macrophages and dendritic cells (Ouyang, Rutz et al. 2011) (O'Garra, Barrat et al. 2008). IL-10 is popular amongst researchers for its extensive role in combating increased inflammation and bone resorption specific to periodontal disease. A study indicated that IL-10 was more predominant in the gingival crevicular fluid of gingivitis patients compared to those who had progressed to periodontitis which suggests the anti-inflammatory nature of IL10 (Feno Al 2014). 
Additionally, IL-10 can contribute to bone homeostasis by maintaining the balance between osteoblastic and osteoclastic activity (Zhang, Chen et al. 2014).

\subsubsection{TGF- $\beta$}

Transforming growth factor $\beta$ (TGF- $\beta$ ), is a multifunctional cytokine that regulates multiple biological processes, including embryonic development, adult stem cell differentiation, immune regulation, wound healing, and inflammation (Lifshitz and Frenkel 2013). After having been quantified in the serum and gingival crevicular fluid of humans with periodontitis, TGF- $\beta$ has been established as an important marker of periodontal disease progression. Higher levels of TGF- $\beta$ were expressed in moderate periodontitis with a gradual decline in levels as the disease became severe. Thus, TGF- $\beta$ has established itself as an important anti-inflammatory cytokine implicated in the pathogenesis of periodontal disease (Skaleric, Kramar et al. 1997).

\subsection{PERIODONTAL DISEASE AND BONE LOSS}

One of the main factors that separate gingivitis from periodontitis is attachment loss, which is an important hallmark of periodontal disease. There is loosening of the tooth from the alveolar bone socket due to destruction of the junctional epithelium (epithelium that connects the tooth to the bone). This bone loss or scientifically 'bone resorption' is caused by none other than bone resorbing cells or osteoclasts.

Osteoclastogenesis is the formation of bone resorbing cells or osteoclasts. Osteoclasts are large multinucleated cells, which are differentiated from the hematopoietic stem cell lineage. They are characterized by presence of multiple nuclei in the cytoplasm and a ruffled border on the cell surface, which is separated from the surrounding tissue by a 
clear zone. This ruffled anatomy is an extensive cell surface area believed to be essential for osteoclastic activity. The clear zone also aids in resorption (Florencio-Silva, Sasso et al. 2015). Secretion of enzymes and other functions related to transport or digestion of products in and out of the cell are done via vacuoles or vesicles (Holtrop and King 1977). Lysozymes are rich in Tartrate-resistant acid phosphatase which is an important biochemical marker of osteoclast function and bone resorption (Halleen, Tiitinen et al. 2006).

On the contrary, osteoblasts are cuboidal cells responsible for bone formation (FlorencioSilva, Sasso et al. 2015). To maintain bone health, osteoblasts and osteoclasts should function in concert. In other words, the amount of bone deposition should be same as the amount of bone resorption (Tanaka, Nakayamada et al. 2005). Any abnormality or imbalance in this activity leads to bone diseases like osteoporosis (Feng and McDonald 2011).

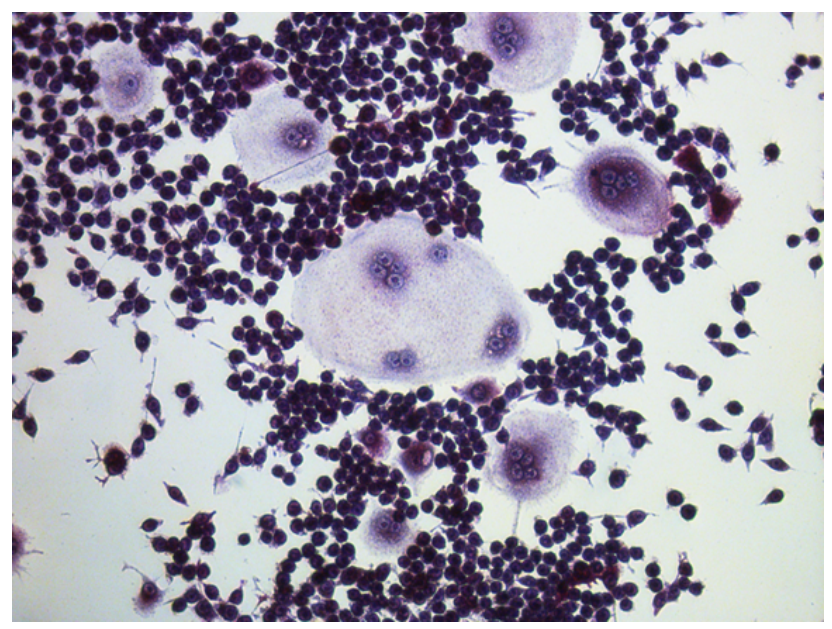

Figure 1. 20x microscopic image of Tartrate resistant acid phosphatase positive (TRAP) osteoclasts characterized by large round appearance and presence of multiple nuclei in the cytoplasm surrounded by RAW 264.7 monocytes. 


\subsection{NF- $\quad$ B SIGNALING PATHWAY AND PERIODONTAL DISEASE}

Nuclear factor kappa B $(\mathrm{NF}-\kappa \mathrm{B})$ is a family of structurally-related proteins or transcription factors which are expressed in response to an inflammatory stimulus (Park, Krishnan et al. 2005). They were first discovered by Sen and Baltimore in 1986 in lymphocytes but later found associated with several mammalian cells (Zhang and Ghosh 2001). These factors are important in regulation of immune and inflammatory responses, cell apoptosis, proliferation, differentiation and survival (Oeckinghaus and Ghosh 2009).

Over-activation of NF- $\kappa \mathrm{B}$ causes the pathogenesis of various diseases like cardiovascular disease, rheumatoid arthritis, cancers, and periodontitis (Nichols, Fischer et al. 2001, Ross, Stagliano et al. 2001, Valen, Yan et al. 2001, Okamoto 2006) (Gilmore, Gapuzan et al. 2002).

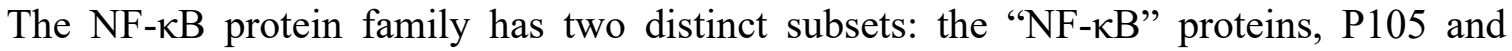
p100, and "Rel” proteins, c-Rel, RelB, and RelA (aka p65). The C-terminal transcription domains on Rel proteins is involved in the transcription process. The NF- $\kappa$ B subfamily proteins form dimers with Rel proteins in order to initiate transcription (Gilmore, 2006). Rel/NF- $\kappa \mathrm{B}$ is activated in response to a wide variety of stimuli like TNF- $\alpha$, IL-1, T-cell activation signals, growth factors, and stress inducers (Barnes and Karin 1997).

Pathways involved in NF- $\kappa$ B activation are broadly classified into 2 main ones Canonical or classical and non-canonical pathway (alternative pathway). The canonical pathway is involved in innate immunity and non-canonical in adaptive immunity (Bonizzi \& Karin 2004). In canonical NF- $\kappa$ B activation, it is compromised of p65 and p50 subunits (Barnes and Karin 1997). Under normal conditions, NF- $\kappa B$ is sequestered in the cytoplasm as an inactive complex with the inhibitory protein IкB (Ghosh et al 1998, 
Gilmore 2006). IKK $\alpha$, IKK $\beta$ and the regulatory protein NF-KB essential modifier (IKK $\gamma$ or NEMO) together constitute the IKK complex (Hacker and Karin 2006). Upon stimulation, IאB is phosphorylated by activated IKK complex, resulting in ubiquitination

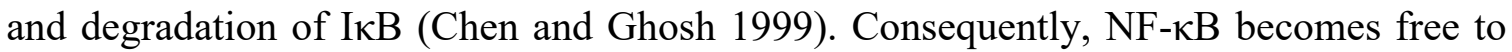
translocate to the nucleus where it initiates the expression of NF-kB-dependent genes (Hayden and Ghosh 2004, Oeckinghaus, Hayden et al. 2011). The broad spectrum of genes that are expressed modulate many physiological processes, in this circumstance, inflammation and host response (Pahl 1999).

On the other hand, non-canonical pathway activates p100/RelB complexes through IKKa-mediated phosphorylation (Beinke, Belich et al. 2002, Karin and Lin 2002, Tergaonkar 2006).

The NF-kB pathway is an important mediator for pro-inflammatory cytokines, chemokines and adhesion molecules (Lawrence 2009). Osteoclast formation also requires the downstream signaling of RANKL/RANK pathway, which is mediated through NF-kB (Yamaguchi, Weitzmann et al. 2012). 


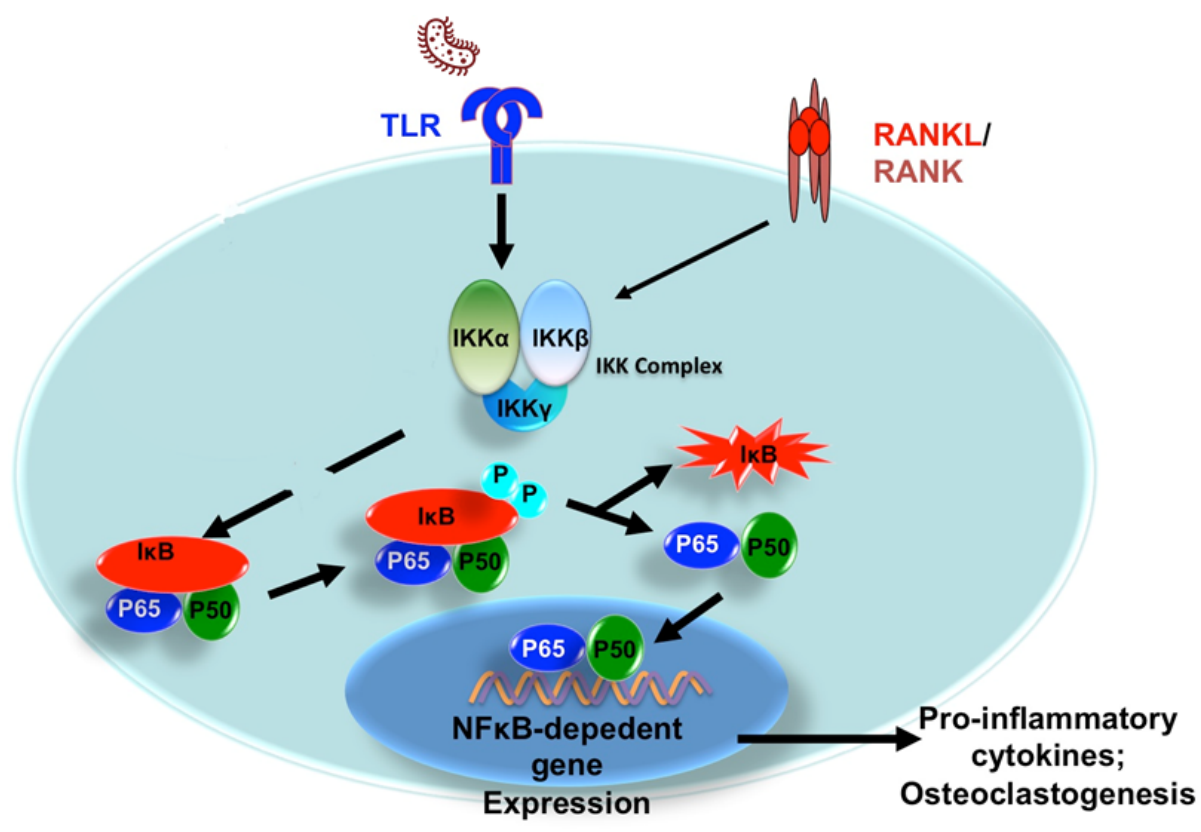

Figure 2. Schematic depiction of the NF-кB pathway.

Binding of pathogen virulence factor to TLR activates NF- $\kappa B$ signaling, which leads to production of pro-inflammatory cytokines. Binding of RANKL to ligand RANK activates

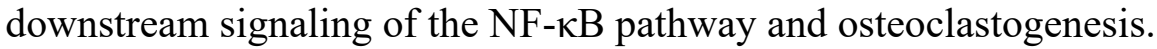

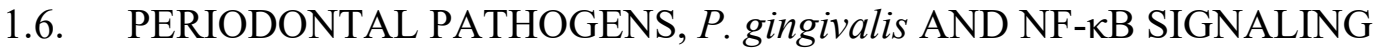 PATHWAY}

NF- $\mathrm{B}$ (Nuclear factor kappa-light-chain-enhancer of activated B cells) pathway is known to be stimulated by bacteria and its byproducts which also regulate around 150 target genes (Pahl 1999). The periodontal bacteria that play pivotal roles in induction of NF-кB signaling are Aggregatibacter actinomycetemcomitans, Fusobacterium nucleatum, Tannerella forsythia (formerly Bacteroides forsythus), Porphyromonas gingivalis, Prevotella intermedia, Treponema denticola. (Kobayashi-Sakamoto, Hirose et al. 2004, Walter, Zahlten et al. 2004) (Hasebe, Yoshimura et al. 2004, Huang, Zhang et 
al. 2004, Kim, Ha et al. 2004, Tiranathanagul, Yongchaitrakul et al. 2004, Tanabe, Bodet et al. 2008). Studies have shown that bacterial lipopolysaccharide (LPS) is responsible for activation of NF-kB pathway (Sen and Baltimore 1986).

\subsection{NF- $\quad$ B SIGNALING PATHWAY AND $P$. gingivalis}

Lipopolysaccharide is the major component of the outer cell membrane (cell wall) of $P$. gingivalis and is a major factor responsible for its virulence potential (Mysak, Podzimek et al. 2014). This biomolecule is particularly of interest to researchers because of its ability to induce the NF-kB signaling pathway and inflammation (Ding, Darveau et al. 2017). LPS is a complex of three segments with highly variable and conserved phosphorylated glucosamine disaccharide regions. They are lipid A which forms the matrix of the outermost membrane, highly variable $\mathrm{O}$ polysaccharide and a conserved core oligosaccharide that links Lipid A to the O -polysaccharide (Raetz and Whitfield 2002). Pathogen-associated molecular pattern (PAMP) are a group of elements specific to the bacteria which get recognized by pattern recognition receptors (PRRs) present on innate immunity cells (Mogensen 2009). Lipid A part of this complex is the bioactive center that is recognized by a pattern recognition receptor, Toll-like receptor 4. LPS

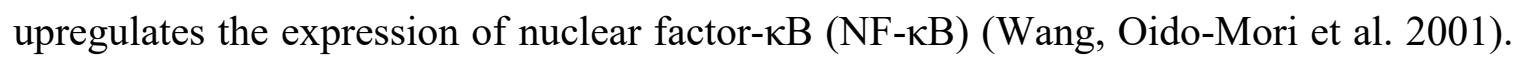
$P$. gingivalis LPS induces production of pro-inflammatory cytokines and osteoclastogenesis through NF-kB (Choi, Moon et al. 2005). This in turn induces periodontal tissue destruction (Mysak, Podzimek et al. 2014). A group of researchers established that $P$. gingivalis disrupted the homeostasis of osteoblasts and osteoclasts by hampering the demineralization process thus leading to alveolar bone loss (Zhang, 
Swearingen et al. 2010). These virulence factors make it very easy for $P$. gingivalis to dwell in periodontal tissues thereby exaggerating the host immune response.

\subsection{NF-kB, OSTEOCLASTOGENESIS, RANKL/RANK/OPG Pathway}

As mentioned earlier, osteoclastogenesis is the process of formation of bone resorbing cells or osteoclasts. The importance of RANKL/RANK pathway has been well documented in regard to osteoclastogenesis. It has been established that NF-kB pathway is downstream of RANKL/RANK pathway which is pivotal in osteoclastogenesis (Boyce 2013).

Receptor activator of nuclear factor (RANK) and its ligand (RANKL) work hand in hand and are well known for their role in bone turnover and immune system (Nagy and Penninger 2015). Discovered in the 1990's, receptor activator of nuclear factor- $\mathrm{kB}$ ligand (RANKL)/RANK/osteoprotegerin (OPG) system is considered a breakthrough in bone biology for exhibiting roles beyond mere osteoclast regulation and survival (Liu and Zhang 2015). Interestingly, it has been located in several other sites such as mammary glands, lymph nodes and brain tissue (Liu and Zhang 2015).

RANK is a type 1 homotrimer transmembrane protein and affiliate of the Tumor Necrosis Receptor Family (TNFR). Osteoclasts and their precursors express RANK, which binding to RANKL to regulate osteoclastogenesis and osteoclast function (Boyce and Xing 2007). Osteoprotegerin (OPG), secreted by osteoblasts and acts as a negative regulation mechanism by blocking the interaction of RANK with RANKL, and thus preventing bone resorption (Boyce and Xing 2007). RANKL/RANK/OPG Pathway is activated via stimulation of NF- $\mathrm{kB}$ and hence is considered the main orchestrator of osteoclastogenesis (Narita, Kobayashi et al. 2009, Florencio-Silva, Sasso et al. 2015). 


\subsection{FRUITS IN HEALTH}

As the famous proverb goes, 'We are what we eat,' food consumption contributes to human health, including the oral health. Fruits and vegetables comprise a massive constituent of food which is universally advocated as healthy. According to dietary guidelines for Americans (2010), one-half of your plate should amount to fruits and vegetables. Fruits are widely accepted as "health foods" because they are rich in dietary fibers, minerals, vitamins, and antioxidants. They are fundamentals in human nutrition as sources of nutrients and non-nutritive food constituents in addition to decreasing risk levels of disease. For decades, fruits have been proved as beneficial for teeth and periodontal tissues. The favorable outcome of fruit on the oral tissues has been attributed to the chewing, exhilarating the salivary flow, and release of several acids which play a major role in maintaining systemic health (Blignaught and Grobler 1992).

\subsection{GRAPES AND ORAL HEALTH}

Researchers are on the quest for finding natural products capable of decreasing oral inflammation by inhibition of the NF-kB pathway. Some of these include fruits like grapes. A diet of grapes, (and fruits in general), is associated with health and reduced inflammation (Nanri, Yamada et al. 2017) (Myint, Welch et al. 2007). Humans have been using grapevine (Vitis spp.) products as early as 3500-2900 B.C. (Bowers et al. 1999). Vitis vinifera also recognized by the common name grape, is the most cultivated food crop worldwide due to its extensive application in wine, dried fruit and juice production (Lodhi and Reisch 1995) (Torregrosa, Bigard et al. 2017). Data reported by the United States; Economic Research Service; US Department of Agriculture states that the U.S. per capita consumption of fresh grapes amounted to 8.1 pounds in 2016. It is one unique 
fruit that is implicated worldwide in health research literature for the presence of several phytonutrients, especially in its skin and seed. Grapes and grape seeds are rich in polyphenolic compounds like monomeric catechin and oligomeric pro-anthocyanidins (Monagas, Gomez-Cordoves et al. 2003). They belong to the family of natural compounds called flavonoids, which are rich in fruits and vegetables and are responsible for imparting the flavor and color (Ross and Kasum 2002). The structure is composed of flavanol units linked by inter-flavan bonds. Flavonoids have gained popularity among researchers due to increased awareness regarding the use of natural products available to combat inflammatory diseases like periodontitis (Ross and Kasum 2002).

Grape comprises a combination of ingredients: (+)-catechin and (-)-epicatechin; (-) epicatechin 3-O-gallate, dimers, trimers, tetramers, and their gallates; and pentamers, hexamers, heptamers, and their gallates (Gabetta, Fuzzati et al. 2000). They possess extensive biological properties, including anti-oxidative, anti-aging, cytoprotective, cardio-protective, anti-tumor, antibacterial, antiviral, and anti-inflammatory (Bagchi, Sen et al. 2003) (Kempuraj, Madhappan et al. 2005) (Middleton, Kandaswami et al. 2000). The antibacterial properties seem to have an effect on oral bacteria and further suppress periodontal inflammation (Bonifait and Grenier 2010). Although the mechanism is still unclear, they are believed to target NF-kB pathway (Yang, Xian et al. 2018), which is an attractive target in many inflammatory diseases like rheumatoid arthritis and cancer (Ross and Kasum 2002). Periodontitis, being a chronic disease of similar inflammatory nature may thus benefit from grape components. Additionally, studies have reported that grape components exhibit little toxicity in vivo and in vitro (Chu Hongqian et al., 2015). 
Nuclear factor-kappaB $(\mathrm{NF}-\mathrm{kB})$ is a crucial transcriptional controller of the inflammatory processes. Numerous investigations have proved that the cytokine genes, namely TNF- $\alpha$, IL-6, and IL-1 $\beta$ are expressed through the activation of NF-kB (Shalit, Halperin et al. 2006, Senthil Kumar and Wang 2009). The murine macrophages cell line RAW 264.7 was discovered 30 years ago from $\mathrm{BALB} / \mathrm{c}$ mice and is considered as an appropriate model for the in-vitro study of macrophages (Raschke et al., 1978). Bacteria stimulate cells to produce reactive oxygen species (ROS). These are critical for bacterial resistance but generate high levels of oxidative stress leading to periodontal tissue and bone destruction. A study showed that grape seed extract (GSE) strongly decreased the production of ROS by LPS-stimulated macrophages (Houde, Grenier et al. 2006).

Osteoclasts are multinucleated cells that play a pivotal role in bone resorption. Involvement of receptor activator of nuclear factor kappaB ligand (RANKL) is responsible for the abnormal activation of osteoclasts (Takayanagi, Iizuka et al. 2000). GSE may intensely inhibit osteoclastogenesis by suppressing osteoclast differentiation and promoting osteoblast differentiation and thus may be beneficial in anti-inflammatory treatment accompanying bone destruction (Park, Park et al. 2012). A question worth addressing is the potential of grape components to positively modulate periodontal health.

\subsection{MICE PERIODONTAL DISEASE MODEL}

Animal models are preferred to study the microbiological, biochemical and immunological aspects of periodontal disease. The mouse is a common model in experimental periodontitis as a critical tool to analyze its pathogenesis and explore potential therapeutic approaches. It bears similarity to man in terms of periodontal anatomy, structure and organization of the tissue, oral sulcular epithelium, junctional 
epithelium, periodontal collagen fibers and alveolar bone. Additionally, development and composition of dental plaque and histopathology of periodontal lesions also bears a striking resemblance to man which makes the murine model a reasonable fit for experimental periodontitis (Klausen 1991).

In summary, periodontitis is one of the most prevalent chronic inflammatory disease. Periodontal pathogens induce production of pro-inflammatory cytokines and osteoclastogenesis through NF-kB signaling which in turn causes periodontal tissue destruction (Choi, Moon et. al 2005). It would be beneficial to find a natural means to down-regulate oral inflammation and bone loss in periodontitis. Grape powder extract contains numerous chemicals of different characteristics and function. Previous literature showed that certain grape components like catechin and pro-anthocyanidins elicit antibacterial and anti-inflammatory properties, while the effect of grape consumption on periodontitis is still unknown. We would like to explore the effects of grape components using in vitro and in vivo methods. The goal of our research was to determine if grape components have an effect on bacterial growth, inflammation and osteoclastogenesis in vitro and inflammation and bone loss in vivo. 


\section{HYPOTHESIS}

We hypothesize that grape powder extract inhibits $P$. gingivalis growth, suppresses proinflammatory cytokine production and inhibits osteoclastogenesis in vitro. We also hypothesize that grape powder inhibits gingival inflammation and prevents bone loss in a murine model. 


\section{CHAPTER 2. MATERIALS AND METHODS}

\subsection{In-vitro EXPERIMENTS}

In order to better understand the benefits of consuming grapes in preventing periodontal diseases, we tested the function of grapes in a series of in vitro experiments. We used grape powder extract, which is produced from whole California grapes and provided by the California Table Grape Commission. California grape extract (1.25 g) was obtained from $250 \mathrm{~g}$ of grape powder (blend of 2011 and 2013 vintages) by adsorption of the hydrophobic compounds, including flavonoids, onto Diaion HP-20 porous sorbent (anion resin), washing with water to remove grape sugars (glucose, fructose) and nondissolvable grape components, and then eluting with methanol. This grape powder extract was further dissolved in an organic solvent Dimethyl Sulfoxide (DMSO) (SigmaAldrich,

St Louis.) as stocking solution before further being diluted in medium as working solution. We used murine RAW 264.7 cells (ATCC CLR-2278) (mouse monocytes) and

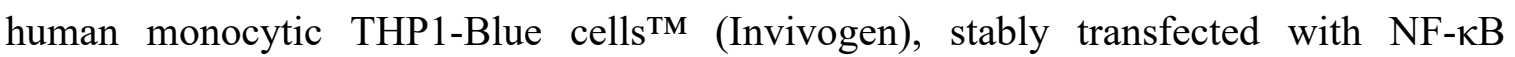
inducible reporter system as model cells to investigate whether grapes can efficiently modulate osteoclastogenesis and pro-inflammatory cytokine production and block NF$\kappa \mathrm{B}$ signaling. The cells were maintained as frozen stocks. RAW 264.7 and THP1-Blue cells $^{\mathrm{TM}}$ were cultured in DMEM (Dulbecco's Modified Eagles Medium) with high glucose. Monocytes can differentiate into macrophages, which play a key role in immune reactions, allergy, and inflammation (St-Denis, Chano et al. 1998). Raw cells can also be 
further differentiated into osteoclasts, and also are capable of producing proinflammatory cytokines important for periodontitis progression (Bertolini, Ottani et al. 2002). RAW 264.7 cells are sensitive, easy to propagate and efficient for DNA transfection (Sigma Aldrich). All these factors provided us the rationale for using the RAW 264.7 cell line since we were interested in studying pro-inflammatory cytokine expression and osteoclastogenesis in our experiments.

P. gingivalis ATCC ${ }^{\circledR} 33277^{\mathrm{TM}}$ was purchased from American Type Culture Collection (Manassas, VA) and maintained as frozen stocks. The medium for $P$. gingivalis was Gifu Anaerobic medium (GAM broth, Tokyo, Japan) and grown under anaerobic conditions $\left(80 \% \mathrm{~N}_{2}, 10 \% \mathrm{H}_{2}\right.$, and $\left.10 \% \mathrm{CO}_{2}\right)$ at $37^{\circ} \mathrm{C}$. The culture plates for $P$. gingivalis were prepared using GAM broth (Nissui Pharmaceutical, Tokyo, Japan), BD Difco Agar ${ }^{\mathrm{TM}}$ (Thermo Fischer Scientific) and 5\% sheep blood (Thermo Fischer Scientific). LPS used was of the form LPS-PG (Ultrapure) obtained from Invivogen. The concentrations of LPS used were $1 \mu \mathrm{g} / \mathrm{ml}$ and $10 \mu \mathrm{g} / \mathrm{ml}$.

\subsubsection{ORAL BACTERIA}

Test the inhibition of bacterial growth by grape extract

An overnight culture of $5 \times 10^{5} \mathrm{CFU} / \mathrm{ml}$ of $P$. gingivalis 3327 (ATCC $®$ ) grown in Gifu anaerobic medium (GAM broth, Tokyo, Japan) at MOI of 10:1 was inoculated into 1.5 $\mathrm{ml}$ micro centrifuge tubes (Eppendorf). The next morning, the $P$. gingivalis was treated with different dosages $(0,0.0625,0.125,0.5 \mathrm{mg} / \mathrm{ml})$ of grape powder extract (California Table Grape Commission). Following serial dilution, $50 \mu 1$ of the culture was plated on blood agar plates. These tubes were incubated at $37^{\circ} \mathrm{C}$ for $24 \mathrm{~h}$. The bacterial growth was 
determined by plating on blood agar in anaerobic conditions for Colony Forming Units (CFU). 7-10 days later, the number of bacterial colonies was counted.

\subsubsection{PRO-INFLAMMATORY CYTOKINE EXPRESSION}

Test the ability of grape powder to prevent $P$. gingivalis induced pro-inflammatory cytokine IL-6 production $10^{5}$ Murine RAW 264.7 cells (ATCC CLR-2278) were stimulated with P. gingivalis LPS overnight in 96 well culture plate. Concentration of LPS used was $1 \mu \mathrm{g} / \mathrm{ml}$. This concentration was in accordance with previous literature and after testing several concentrations to achieve a reasonable IL-6 signal. Initially the cells were treated with different dosages $(0,25,50,100 \mu \mathrm{g} / \mathrm{ml})$ of grape powder extract and incubated at $37{ }^{\circ} \mathrm{C}$ for an hour. One hour later the cells were stimulated with LPS. LPS used was in an ultrapure form obtained from $P$. gingivalis (Invivogen). Cell culture supernatant was harvested after incubating overnight. The supernatant was tested for the expression of the

critical cytokine, IL-6, using enzyme linked immunosorbent assay (BD biosciences, San Diego, CA).

\subsubsection{P. gingivalis LPS INDUCED NF-kB ACTIVATION}

To test the ability of THP1-Blue cells ${ }^{\mathrm{TM}}$ to block $P$. gingivalis LPS-induced NF- $\mathrm{kB}$ activation

$10^{5}$ THP1-Blue cells TM (Invivogen) were treated with different dosages $(0,25,50,200$ $\mu \mathrm{g} / \mathrm{ml}$ ) of grape powder extract in a 96 well culture plate and incubated at $37^{\circ} \mathrm{C}$ for an hour. One hour later the cells were stimulated with LPS. LPS used was in an ultrapure 
form obtained from P. gingivalis (Invivogen). Concentration of LPS used was $10 \mu \mathrm{g} / \mathrm{ml}$. This concentration was chosen after testing several concentrations to achieve an appropriate level of NF-kB activation. Cell culture supernatant was harvested after incubating overnight. Activity of NF-kB-inducible alkaline phosphatase was determined by colorimetric activation at a 1-hour time point using Quanti Blue reagent.

\subsubsection{OSTEOCLASTOGENESIS}

Test the inhibition of osteoclastogenesis by grape extract $10^{3}$ murine monocyte cell line (RAW 264.7 cells) was cultured in 96-well plates in $150 \mu \mathrm{l}$ of $\alpha$-MEM medium supplemented with $10 \%$ fetal bovine serum (FBS), $1 \%$ penicillinstreptomycin, and $100 \mathrm{ng} / \mathrm{ml}$ murine soluble RANKL (sRANKL) (Peprotech). $200 \mu \mathrm{g} / \mathrm{ml}$ of grape powder extract was added into the cell culture. Seven days later, the cultures were fixed in $10 \%$ formalin and stained for the enzyme tartrate-resistant acid phosphatase (TRAP), an osteoclast marker, using the Leukocyte Acid Phosphatase TRAP kit (SigmaAldrich ${ }^{\circledR}$ ) for 15 minutes. The number of multinucleated TRAP-positive cells in each well were counted microscopically which represented the multinucleated osteoclasts (Jacome-Galarza, Lee et al. 2013).

\subsection{In-vivo EXPERIMENTS}

\subsubsection{MICE}

Mice of 8-10 weeks old were purchased from Jackson lab and used in the experiments. Mice strain used was C57BL/6 mice model for the ligature model and BALB/c mice for the Baker model. C57BL/6 mice have been reported to show resistance to bone loss in the Baker model (Baker, Dixon et al. 2000). All these factors favor the use of. BALB/c strain 
in the baker model. Animals were kept in animal facilities at the University of Louisville. All handling and processing were approved by Institutional Animal Care Committee, and in appliance with the established Federal and State policies.

\subsubsection{MURINE LIGATURE INDUCED PERIODONTITIS MODEL}

Ligature induced periodontitis model is a straightforward procedure used to induce alveolar bone loss in mice. A silk ligature is tied around typically the maxillary second molar, placed in the gingival sulcus. This specific site has been highlighted as appropriate for maximum data validity and reproducibility (Abe and Hajishengallis 2013). Ligatureinduced periodontitis model is selected because of its ability to induce periodontitis in a shorter period of time by promoting inflammation and bone loss. The ligature acts as a niche for bacterial plaque and facilitates bacterial accumulation and inflammation.(Abe and Hajishengallis 2013) (Graves, Fine et al. 2008, Oz and Puleo 2011). It is also advantageous in terms of predictability of events and duration resulting in alveolar bone loss (Graves, Fine et al. 2008) (Li and Amar 2007) (Bezerra, de Lima et al. 2000). We were particularly interested in studying inflammatory response in the ligature model due to its ability to induce strong and intense inflammation in a shorter time period (Abe and Hajishengallis 2013).

Mice were weighed prior to the experiments. Grape powder diet consumed by the select mice group was specially formulated by California Table Grape Commission by adding $5 \%$ grape powder to the regular mouse diet. Diet was prepared in accordance with calculating mouse body weight and average human consumption of grape by humans. 


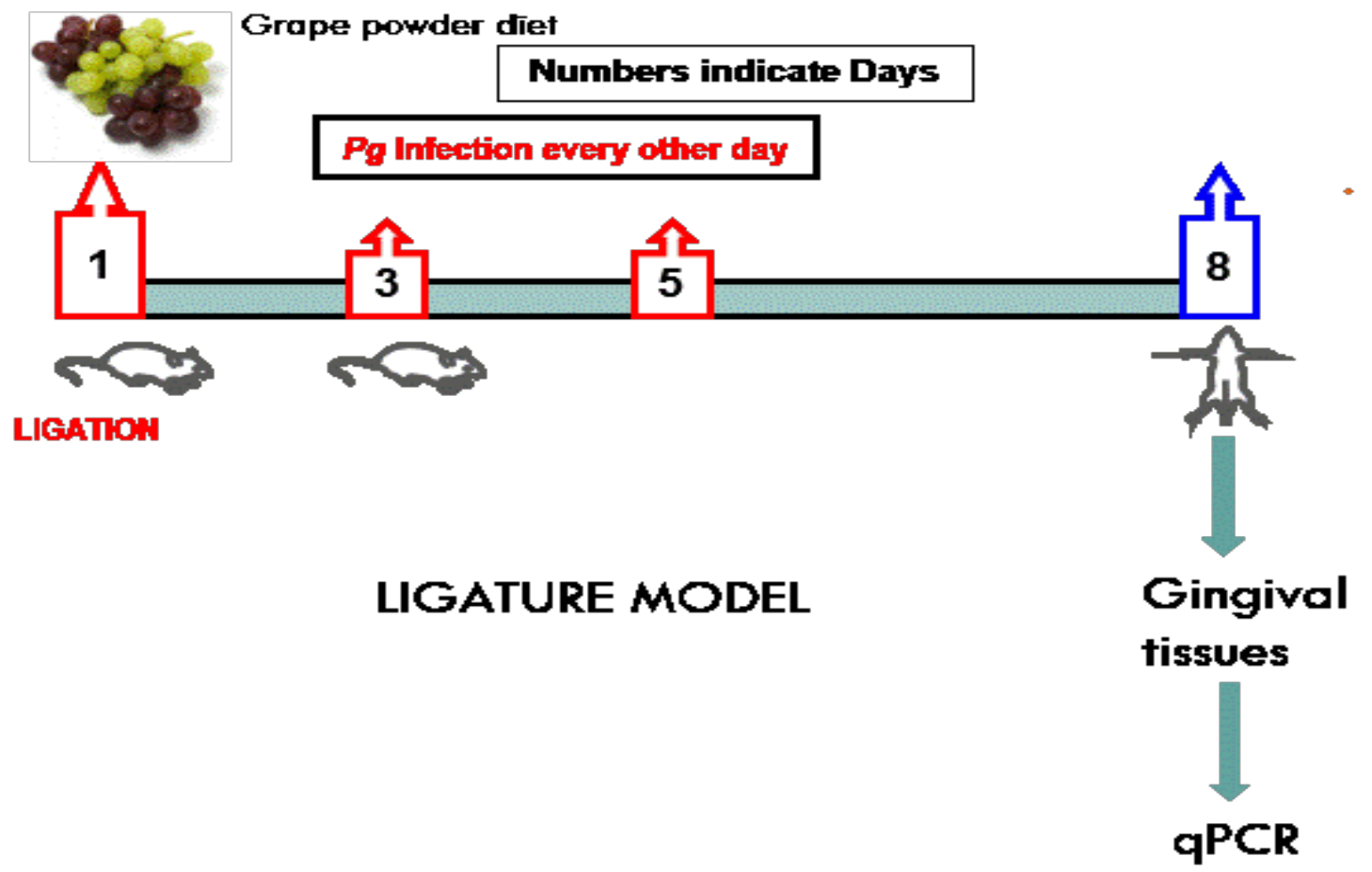

Figure 3. Schematic depiction of the protocol for periodontitis induction in vivo using ligature model on C57BL/6 mice.

The mice were ligated with 6-0 black silk suture on day 1 and infected with $10^{9}$ colonyforming units (CFU) of $P$. gingivalis (33277) in $2 \%$ carboxymethylcellulose (CMC) (day 1,3 and 5) followed by sacrifice of mice on day 8 . The mice were fed with grape powder diet (mouse food fortified with 5\% grape powder) or control diet. Gingival tissues were harvested to check expression of pro and anti- inflammatory cytokines by qPCR. Numbers indicate the days.

There were 4 groups of mice: 1 . Sham + Control (no ligation, no $P$. gingivalis infection, control diet), 2. Ligated + Control (ligation $+P$. gingivalis infection + control diet), 3 . Sham + Grape (no ligation, no $P$. gingivalis infection, on grape powder diet), 4. Ligated + Grape (ligation $+P$. gingivalis infection + grape powder diet) Each group had 5 mice 
which was calculated according to a power analysis that required sample size was 5 mice for a statistical power of $80 \%$.

On the first day, mice groups 2 and 4 were ligated using a 6-0 black silk suture around the maxillary second molar placed in the gingival sulcus. Additionally, the same mice groups were orally infected (oral gavage) with $1 \times 10^{9}$ colony-forming units (CFU) of $P$. gingivalis (3327; American Type Culture) in $2 \%$ carboxymethylcellulose (CMC) to facilitate adhesion of the bacteria and then infected for a total of 3 times every other day. Infection was done using a gavage needle around the maxillary molars on both sides. Mice groups 3 and 4 consumed a mouse food diet fortified with grape powder (5\%) obtained from California Table Grape Commission. Mice in groups 1 and 2 were fed with regular or control diet. The mice were kept for seven days. On the eighth day, the mice were sacrificed, and gingival tissues were harvested. Gingival expression of periodontal markers was determined by Quantitative Real-time PCR. Numbers indicate the days.

\subsubsection{BAKER MODEL}

Another model was developed by Baker and his team in which mice are orally infected with P. gingivalis leading to alveolar bone loss (Baker, Evans et al. 1994). This model allows for controlled environmental conditions and infection levels (Hart, Shaffer et al. 2004). It is aimed at allowing mice to naturally develop periodontitis over a period of time similar to development of periodontitis in humans. It closely mimics the chronic nature of periodontitis. Alveolar bone loss is detected after 10 weeks. Apart from being a fairly inexpensive and experimentally induced disease model, mice possess a similar molar structure to humans (Oz and Puleo 2011). All these factors make the baker model a 
favorable model to detect bone loss levels in mice after being orally infected with $P$. gingivalis.

Grape powder diet consumed by the select mice groups was specially formulated by California Table Grape Commission by adding 5\% grape powder extract to the regular mouse diet. Diet was prepared in accordance with calculating mouse body weight and average human consumption of grape by humans.

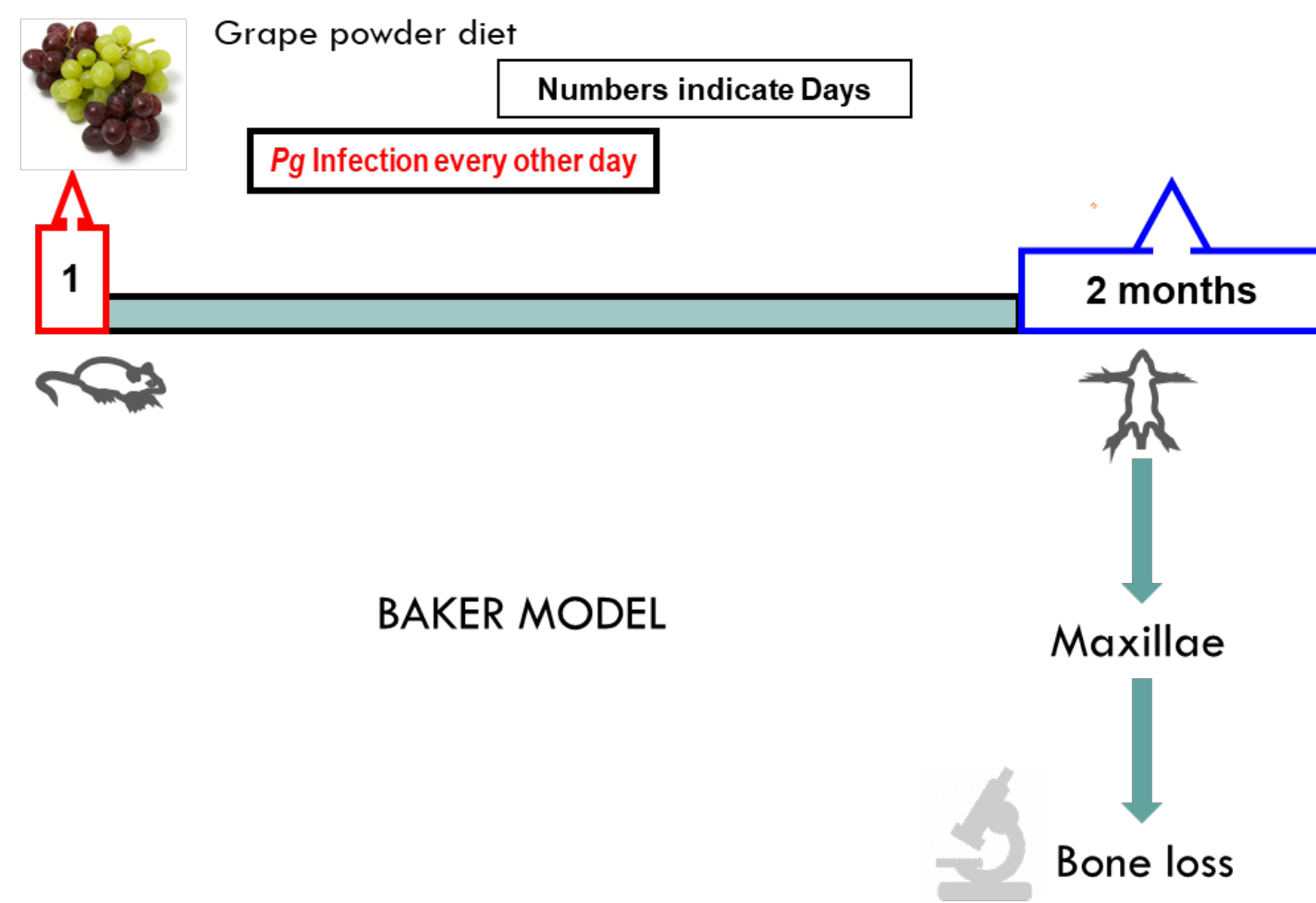

Figure 4. Schematic depiction of the protocol for periodontitis induction in vivo using baker model on BALB/c white mice.

Grape powder diet (mouse food fortified with 5\% grape powder) and $10^{9}$ colony-forming units (CFU) of $P$. gingivalis (3327) oral infection in $2 \%$ carboxymethylcellulose (CMC) around maxillary molar teeth 5 times a day for 8 days followed by sacrifice of mice after 
2 months and subsequent harvest of maxillary skulls to check bone loss microscopically. Numbers indicate the days.

There were 4 groups of mice -1 . Sham + Control (no P. gingivalis infection + control diet), 2. P. gingivalis + Control (P. gingivalis infection + control diet), 3. Sham + Grape (grape powder diet), 4. $P$. gingivalis + Grape $(P$. gingivalis infection + grape powder diet). Each group had 5 mice which was calculated according to a power analysis that required sample size was 5 mice for a statistical power of $80 \%$ bone loss.

Mice groups 2 and 4 were orally infected (oral gavage) with $1 \times 10^{9}$ colony-forming units (CFU) of $P$. gingivalis (3327; American Type Culture) in $2 \%$ carboxymethylcellulose (CMC) to facilitate adhesion of the bacteria and then infected for a total of 5 times every other day for 8 days. Infection was done using a gavage needle around the maxillary molars on both sides. Mice groups 3 and 4 consumed a mouse food diet fortified with grape powder (5\%) obtained from California Table Grape Commission. Mice groups 1 and 2 consumed a regular or control diet. The mice were kept for 2 months allowing the $P$. gingivalis to grow and colonize the oral cavity. After 2 months, the mice were sacrificed with $3 \%$ isoflurane $(40 \mathrm{mg} / \mathrm{kg})$ followed by cervical dislocation. Maxillary jaw bones were harvested. Numbers indicate the days.

\subsubsection{GINGIVAL TISSUE HARVEST IN LIGATURE MODEL}

Gingival tissues of the mice were excised from around the maxillary molars for mRNA harvest. These tissues were immersed in buffer RLT (Qiagen). The gingiva samples were frozen at -80 degree till ready for RNA isolation. RNA was isolated using RNeasy Mini kit (Qiagen). RNA was reverse-transcribed using the High-capacity cDNA Archive Kit 
(Applied Biosystems, Foster city, CA, USA) and qPCR was performed using the ABI 700 System, following the manufacturers protocol (Applied Biosystems). mRNA expression of pro-inflammatory markers - IL-6, TNF- $\alpha$, IL-17, IL-1 $\beta$ and antiinflammatory markers - TGF- $\beta$ and IL-10 were determined by quantitative Real-time PCR.

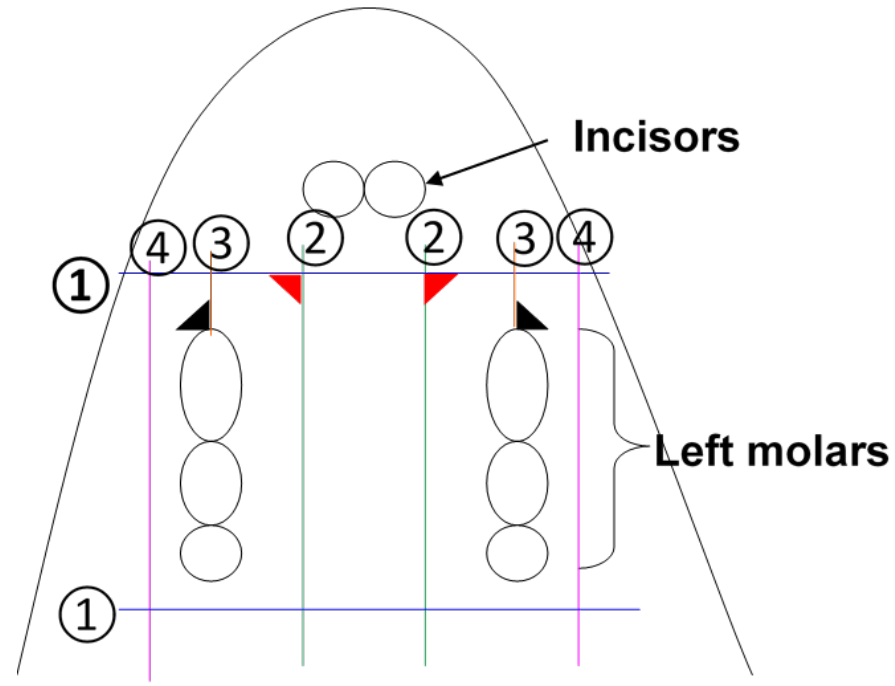

Figure 5. Schematic depiction of mice maxilla showing molar and incisor teeth and surrounding gingiva.

Numbers indicate the incision sites made. Incision (1), (2), (3) were made first. The red triangle part of the gingiva was grasped, and the lingual part of gingiva was pulled. Then, incision (4) was made and the black part of the gingiva grasped, and the buccal part of the gingiva pulled. 


\subsubsection{HARVEST OF MAXILLARY JAW BONE AND ALVEOLAR BONE LOSS}

EVALUATION IN BAKER MODEL

The harvested skulls from Baker model mice were immersed in water and subjected to boiling at $15 \mathrm{psi}$ for 10 minutes. During the process of de-fleshing, the maxillae were detached from the skulls. Maxillae were cleaned gently with micro brushes and water and immersed overnight in $3 \%$ hydrogen peroxide. The following morning, the skulls were washed in water, cleaned again and left to air-dry. Once completely dry, the skulls were stained with $0.5 \%$ eosin for 5 minutes followed by $1 \%$ methylene blue for 1 minute (Both bought from Ricca Chemical Company, TX, USA).

Distance from cementoenamel junction to alveolar bone crest $(\mathrm{CEJ} / \mathrm{ABC})$ on second molar (three sites corresponding to mesial-buccal cusp, buccal groove, and disto-buccal cusp) and the sites corresponding to mesio-buccal cusp, disto-buccal cusp and distal groove of the first molar, and buccal cusp of the third molar were measured. This was done on the left and right buccal side. To calculate pro-inflammatory periodontal bone loss, the mean CEJ-ABC distance from the group of control mice was subtracted from the CEJ-ABC distance for each experimental group of mice. Bone loss was visualized by methylene blue/eosin staining and quantified using a Nikon SMZ 800 dissecting microscope (40X, Nikon Instruments Inc., Melville, NY, USA) fitted with a Boeckeler VIA-170K video image marker measurement system (Boeckeler Instruments Inc, Tucson, AZ, USA). The results were presented in $\mathrm{mm}$; the values indicated bone loss relative to controls. 


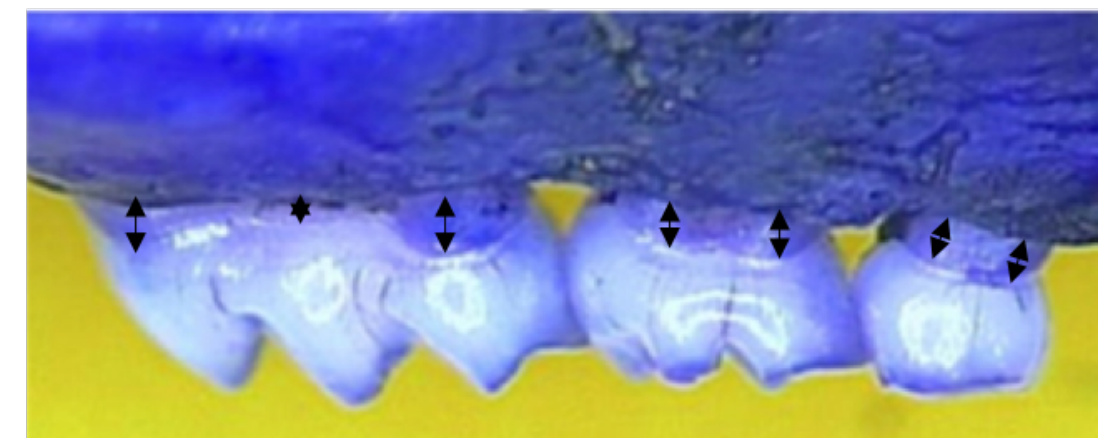

Figure 6. Microscopic picture of mice maxillary teeth showing the seven sites of measurement from the CEJ to ABC (depicted by black arrows) on the right buccal side after staining with methylene blue for visualization of the CEJ (Baker model).

Arrows indicate the site of measurement from the CEJ to ABC. Measurements for all four groups of mice were taken at fourteen different sites, 7 sites each on the right and left side of the maxillary arch - the mesio-buccal cusp, buccal groove, and disto-buccal cusp of the ligated $2^{\text {nd }}$ molar, mesio-buccal cusp, disto-buccal cusp and distal groove of the first molar, and buccal cusp of the third molar. Bone loss in the baker model was calculated by subtracting the fourteen - site total CEJ-ABC distance of group Sham control from group $P$. gingivalis control and group Sham grape from group $P$. gingivalis grape. The results were presented in $\mathrm{mm}$; the values indicated bone loss relative to controls.

\section{3. $\quad$ STATISTICAL ANALYSIS}

Data were evaluated by two-tailed t test. (InStat v3.06 program, GraphPad) and differences were considered statistically significant at the $p<0.05$ level.

Human Subjects: No human subjects were used in the experiment. 


\section{CHAPTER 3.RESULTS}

\subsection{In-vitro}

The aim of this research was to evaluate the ability of grape powder extract to inhibit $P$. gingivalis growth, suppress pro-inflammatory cytokines and inhibit osteoclastogenesis in vitro. We also aimed to investigate the therapeutic nature of grape powder to inhibit gingival inflammation and prevent bone loss in a murine model.

\subsubsection{GRAPE POWDER EXTRACT INHIBITS $P$. gingivalis GROWTH.}

The role of $P$. gingivalis as one of the key players in the pathogenesis of periodontal disease cannot be ignored. LPS from periodontal pathogen $P$. gingivalis signal through Toll-like receptors, activate the NF- $\mathrm{BB}$ pathway, and induce periodontal inflammation (Coats, Reife et al. 2003). We were thus interested in studying the effect of grape powder extract on $P$. gingivalis growth. Grape powder extract was prepared using DMSO as a solvent. In order to confirm that DMSO was not responsible for decrease in the levels of IL-6, corresponding concentrations of DMSO were treated with P. gingivalis LPS. 


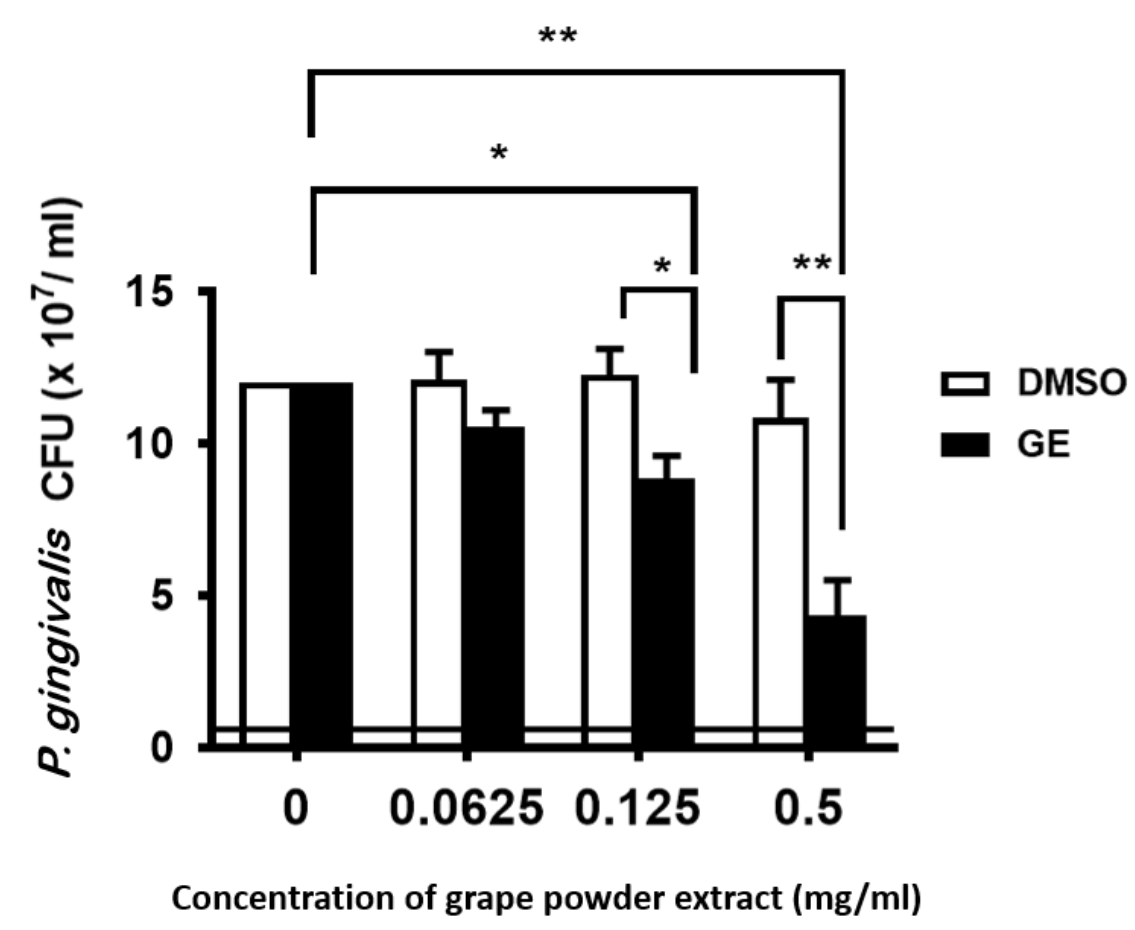

Figure 7. Graphical comparison of $P$. gingivalis growth after treatment with different concentrations of grape powder extract.

$P$. gingivalis were treated with increasing dosages of grape powder extract and incubated anaerobically overnight after which the culture was plated on blood agar plates. After a 710-day anaerobic incubation, the plates were counted for colony forming units (CFU). Group of plates inoculated with $P$. gingivalis only and DMSO were the controls. Asterisks indicate statistically significant differences $(*, p<0.05 ; * *, p<0.01)$ between the labelled groups. Data was evaluated by two tailed $t$ test.

Grape powder extract was prepared using DMSO as a solvent. In order to confirm that DMSO was not responsible for inhibition of $P$. gingivalis growth, $P$. gingivalis was treated with corresponding concentrations of DMSO as controls.

In Fig 7., P. gingivalis with $0.125 \mathrm{mg} / \mathrm{ml}$ and $0.5 \mathrm{mg} / \mathrm{ml}$ concentration of grape powder extract exhibits a significant reduction in $\mathrm{CFU}$, as compared to $P$. gingivalis without 
grape powder extract treatment. $P$. gingivalis with $0.125 \mathrm{mg} / \mathrm{ml}$ and $0.5 \mathrm{mg} / \mathrm{ml}$ concentration of grape powder extract exhibit significantly less CFU formation as compared to their corresponding DMSO concentrations. This clearly indicates that DMSO in the grape powder extract is not responsible for reduction in the growth of $P$. gingivalis. Although P. gingivalis treated with $0.0625 \mathrm{mg} / \mathrm{ml}$ concentration of grape powder has a reduction in CFU as compared to $P$. gingivalis without treatment of grape powder extract, the difference is not statistically significant. Also, its difference with corresponding DMSO is not statistically significant. From this data we can conclude that grape powder extract inhibits the growth of $P$. gingivalis.

\subsubsection{GRAPE POWDER EXTRACT INHIBITS P. gingivalis- LPS INDUCED PRO- INFLAMMATORY CYTOKINE PRODUCTION}

As reported previously, pro-inflammatory cytokines and chemokines play a major role in the pathogenesis of periodontitis, we wanted to investigate whether grape powder extract will inhibit the expression of cytokine, IL-6, which is critical in periodontitis. Grape powder extract was prepared using DMSO as a solvent. In order to confirm that DMSO was not responsible for decrease in the levels of IL-6, corresponding concentrations of DMSO were treated with $P$. gingivalis LPS. 


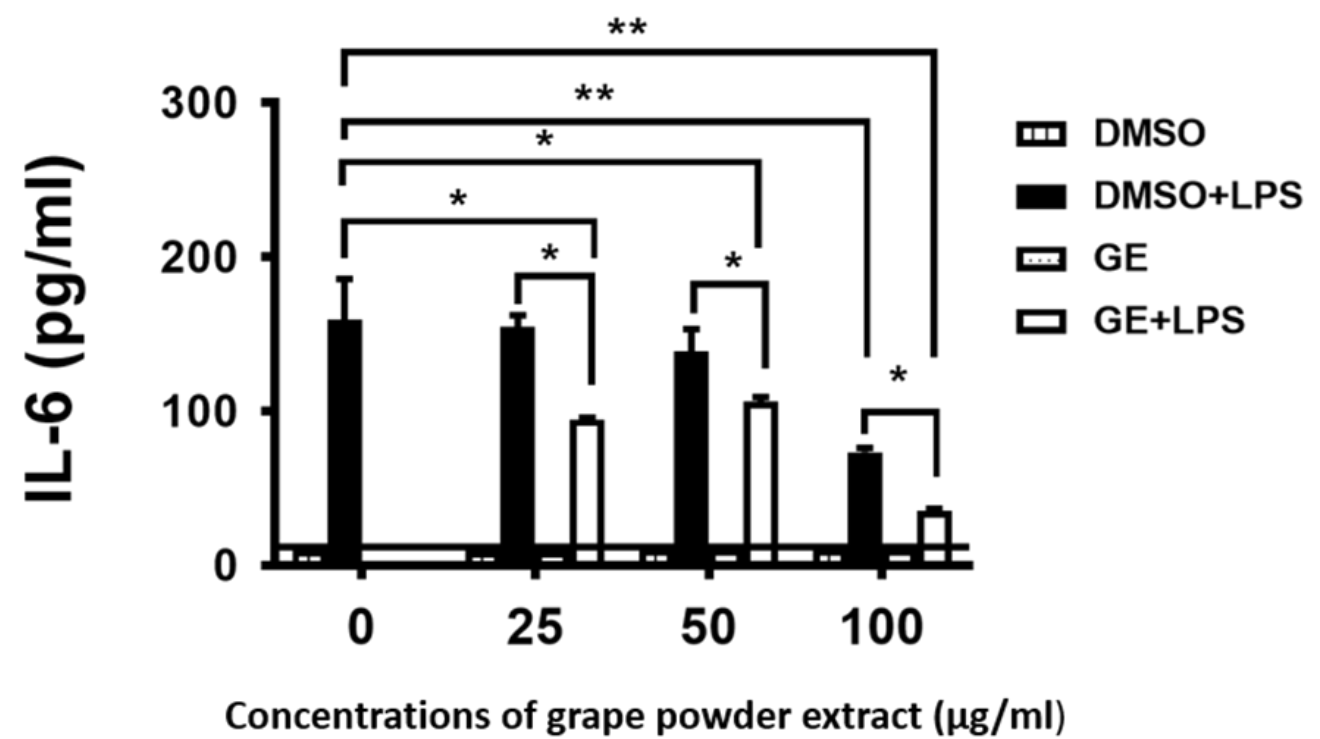

Figure 8. Comparison of different concentrations of grape powder extract and DMSO on $P$. gingivalis-LPS induced pro-inflammatory cytokine IL-6 production in RAW 264.7 cells.

RAW 264.7 cells were treated with different dosages of grape powder extract. Cells were incubated at $37^{\circ} \mathrm{C}$ for 1 hour and then treated with $P$. gingivalis LPS at a concentration of $1 \mu \mathrm{g} / \mathrm{ml}$. Cells were incubated at $37^{\circ} \mathrm{C}$ overnight and supernatant was measured for IL6 using ELISA. Cells treated with DMSO were used as controls. IL-6 production by the cells without any stimulation nor treatment was labeled out as the baseline. Asterisks indicate statistically significant differences $(*, \mathrm{p}<0.05 ; * *, \mathrm{p}<0.01)$ between the labelled groups. Data were evaluated by two tailed t test.

In fig 8., Grape powder extract and DMSO alone at concentrations of $0,25,50,100$ $\mu \mathrm{g} / \mathrm{ml}$ showed minimal expression of IL- 6 indicating that they were not capable of causing any harm on their own. Expression of IL-6 with $P$. gingivalis LPS without treatment of grape powder extract (0) is the highest. Expression of $P$. gingivalis LPS 
induced IL-6 with 25,50 and $100 \mu \mathrm{g} / \mathrm{ml}$ of grape powder extract treatment exhibits a significant reduction, as compared to IL-6 produced without treatment of grape powder extract. At concentrations of $25,50,100 \mu \mathrm{g} / \mathrm{ml}$ of grape powder extract treatment, LPSinduced IL-6 production was significantly reduced compared with the ones treated with corresponding DMSO. Treatment with $25 \mu \mathrm{g} / \mathrm{ml}$ and $50 \mu \mathrm{g} / \mathrm{ml}$ of DMSO did not induce statistically less IL-6 production. This indicates that DMSO in the grape powder extract is not responsible for reduction in IL-6. From this data we can conclude that grape powder extract inhibits IL-6 production in RAW 264.7 cells.

\subsubsection{GRAPE POWDER EXTRACT INHIBITS $P$. gingivalis LPS-INDUCED NF- $\mathrm{kB}$}

\section{ACTIVATION.}

Although the mechanism is still unclear, some grape components are believed to target the nuclear factor-kappaB (NF-kB) signal transduction pathway, which is an attractive target in many inflammatory diseases like rheumatoid arthritis and cancer.

THP1-Blue cells ${ }^{\mathrm{TM}}$ are designed in a way as to monitor the NF- $\mathrm{\kappa B}$ signal transduction pathway in physiologically relevant cell lines. THP1-Blue cells ${ }^{\mathrm{TM}}$ were derived from the human THP-1 monocyte cell line and stably transfected with an NF-kB-inducible SEAP (secreted embryonic alkaline phosphatase) reporter construct. This enables the monitoring of NF- $\mathrm{\kappa B}$ activation by determining the activity of SEAP. 


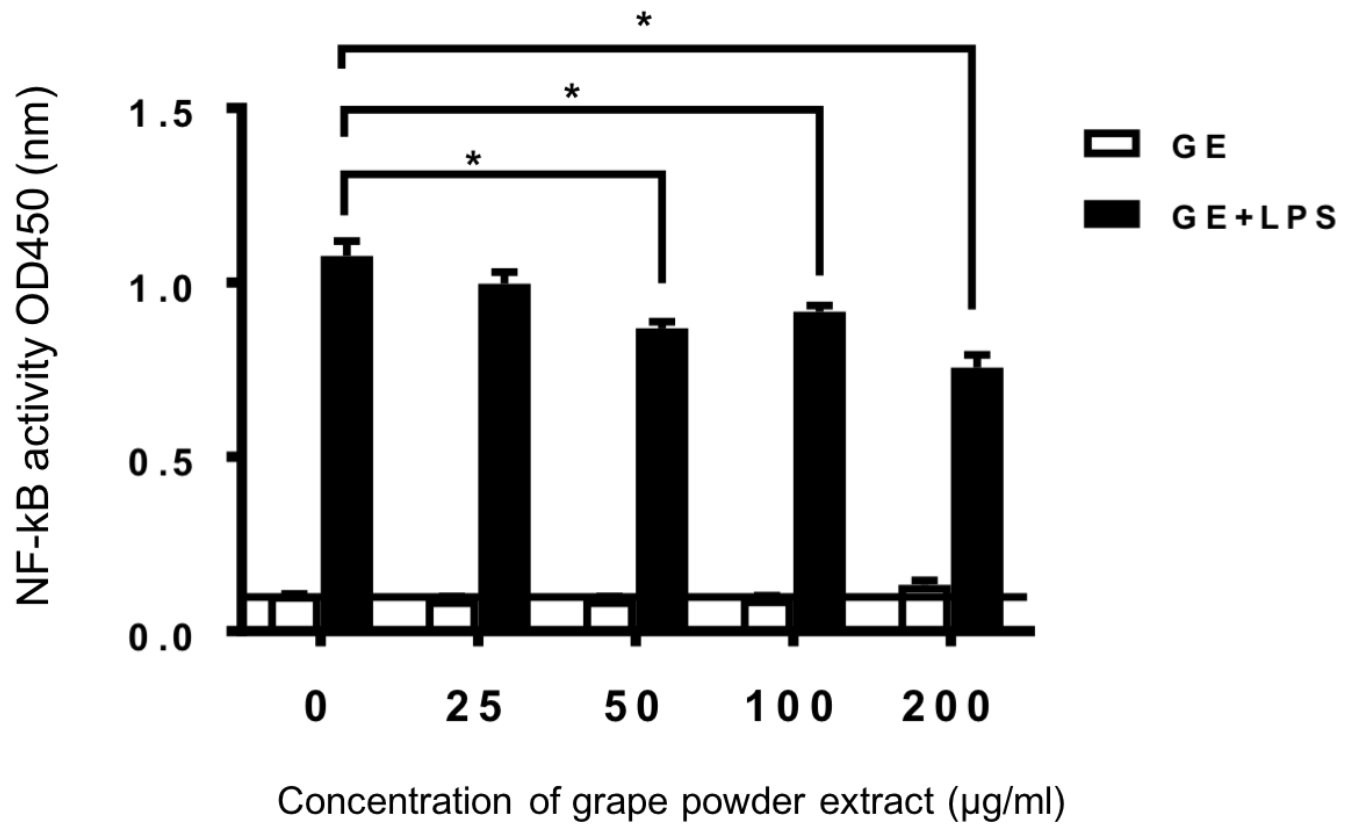

Figure 9. Comparison of level of $P$. gingivalis LPS-induced NF-кB activation at different concentrations of grape powder extract in THP1-Blue cells ${ }^{\mathrm{TM}}$.

THP1-Blue cells ${ }^{\mathrm{TM}}$ were treated with different dosages of grape powder extract. Cells were incubated at $37{ }^{\circ} \mathrm{C}$ for 1 hour and then treated with $P$. gingivalis LPS at a concentration of $10 \mu \mathrm{g} / \mathrm{ml}$. Cells were incubated overnight, and supernatant was harvested. Cells treated with grape powder extract alone is indicated by the baseline. Activity of NF-kB-inducible alkaline phosphatase was determined by colorimetric activation using a detection reagent Quanti-blue at a 1-hour time point. Asterisks indicate statistically significant differences $(*, p<0.05)$ between the labelled groups. Data were evaluated by two tailed $t$ test.

In fig 9., The amount of NF-kB activation by THP1-Blue cells ${ }^{\mathrm{TM}}$ treated with only grape powder extract at different concentrations showed minimal activity of NF- $\mathrm{kB}$ indicating that the grape powder extract was not capable of causing any activation on its own. With 
no grape powder extract treatment, THP1-Blue cells ${ }^{\mathrm{TM}}$ stimulated with LPS showed highest level of NF- $\mathrm{B}$ activation. After treated with grape powder extract at concentrations of 50, 100 and $200 \mu \mathrm{g} / \mathrm{ml}$, LPS-stimulated THP1-Blue cells ${ }^{\mathrm{TM}}$ showed significant reduction in the activity of $\mathrm{NF}-\kappa \mathrm{B}$ as compared with THP1-Blue cells $\mathrm{T}^{\mathrm{TM}}$ stimulated with LPS alone. From this data we can conclude that grape powder extract inhibits $P$. gingivalis LPS-induced NF- $\kappa$ B activation in THP1-Blue cells ${ }^{\mathrm{TM}}$.

\subsubsection{GRAPE POWDER EXTRACT INHIBITS RANKL-INDUCED} OSTEOCLASTOGENESIS

It has been established that alveolar bone loss is caused by the imbalance between bone

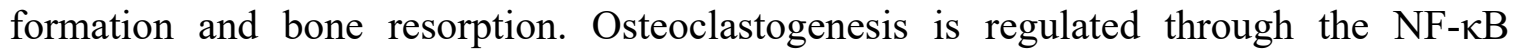
pathway that is downstream of RANKL/RANK pathway. We explored the ability of grape powder extract to directly prevent osteoclastogenesis in vitro. RAW 264.7 cells are well-established among researchers to study the differentiation of osteoclasts (JacomeGalarza, Lee et al. 2013). Hence, the murine RAW 264.7 cell line was chosen as ideal for this assay. In order to determine the number of TRAP positive osteoclasts, they were counted microscopically in each well. Osteoclasts are characterized by the presence of three or more nuclei in the cytoplasm and so cells exhibiting this distinct feature were chosen. The number of osteoclasts in each well was counted under the microscope. Our results proved that grape powder extract was able to effectively reduce osteoclastogenesis (Fig. 10 and Fig. 11). 


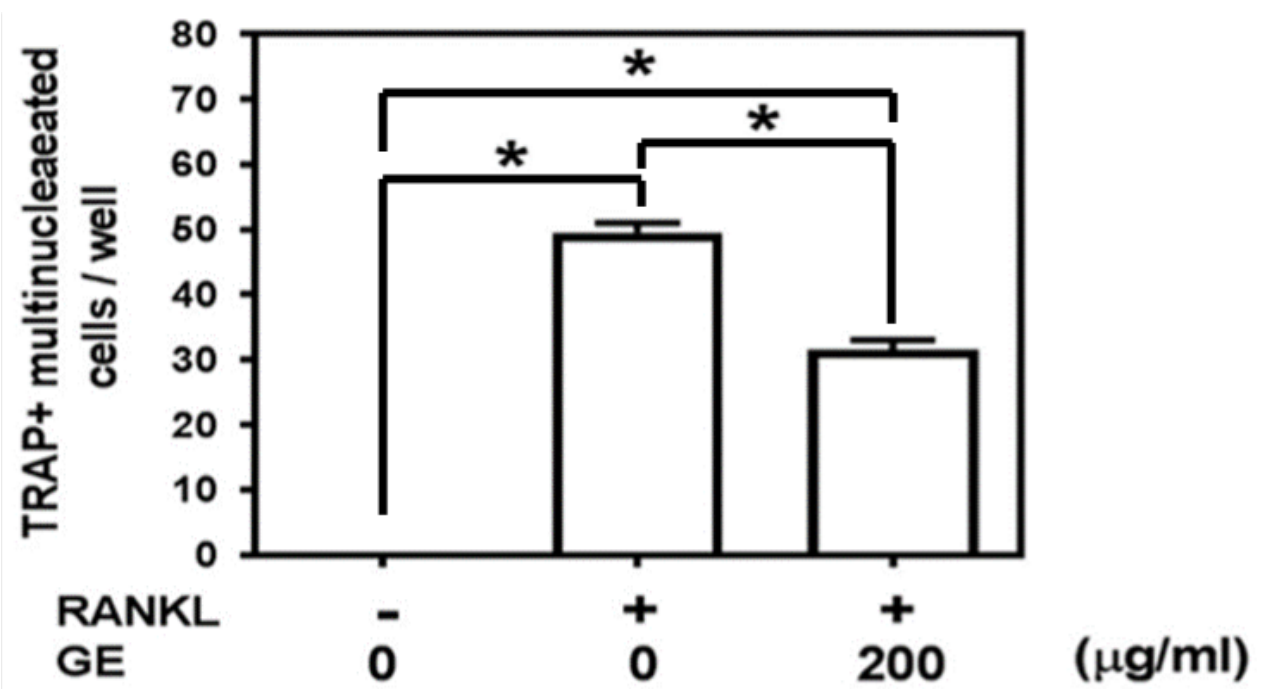

Figure 10. Comparison of number of osteoclasts produced in RAW 264.7 cells with RANKL at 0 and $200 \mu \mathrm{g} / \mathrm{ml}$ of grape powder extract and RAW 264.7 cells without RANKL and grape powder.

RAW 264.7 cells were treated with $100 \mu \mathrm{g} / \mathrm{ml}$ of RANKL and $200 \mu \mathrm{g} / \mathrm{ml}$ of grape powder extract. Untreated (RANKL only) and no RANKL or no grape powder extract were used as controls. The cells were cultured for 7 days and then stained with TRAP for 15 minutes. Multinucleated TRAP positive cells were counted per well under the microscope. Asterisks indicate statistically significant differences $(*, p<0.05)$ between the labelled groups. Data were evaluated by two tailed t test.

In Fig 10., RAW 264.7 cells showed no formation of Multinucleated TRAP positive cells without the presence of RANKL. This indicates that RANKL is indeed critical for the formation and differentiation of osteoclasts. Untreated (RANKL only) RAW 264.7 cells showed the highest number of Multinucleated TRAP positive cells which was expected since RANKL plays a pivotal role in regulating the RANKL/RANK pathway towards osteoclastogenesis. RANKL only RAW 264.7 cells, when compared to untreated and 
without RANKL RAW 264.7 cells show a significant increase in number of Multinucleated TRAP positive cells. Although RAW 264.7 cells treated with RANKL and $200 \mu \mathrm{g} / \mathrm{ml}$ of grape powder extract show a significant increase in number of multinucleated TRAP positive cells when compared to untreated and without RANKL RAW 264.7 cells, they also showed a significant reduction when compared to untreated (RANKL only) RAW 264.7 cells. Our results proved that grape powder extract was able to effectively reduce osteoclastogenesis.

(A) Untreated cells

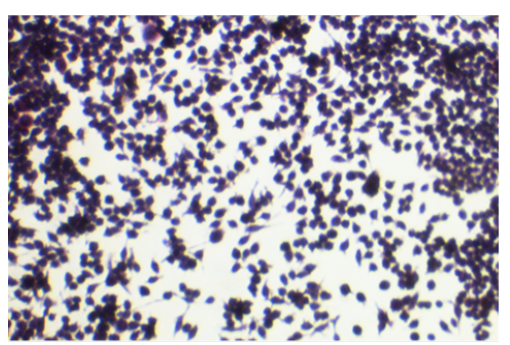

(B) RANKL

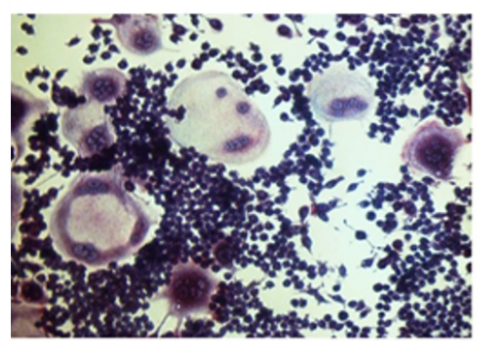

(C) Grape powder extract

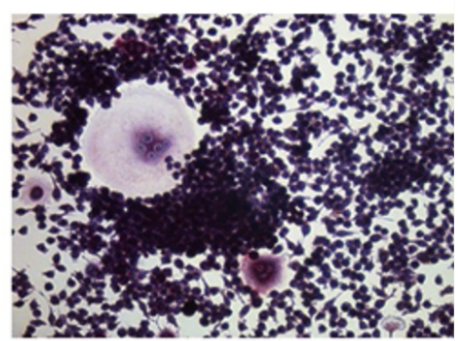

Figure 11. 20x microscopic images showing comparison of number of TRAP positive osteoclasts produced in a 96 well plate in 3 different conditions

A) Untreated RAW 264.7 cells, B) RAW 264.7 cells treated with RANKL only and C) RAW 264.7 cells treated with RANKL and $200 \mu \mathrm{g} / \mathrm{ml}$ of grape powder extract. The number of TRAP positive osteoclasts per well was counted under the electron microscope. Image $\mathrm{C}$ depicts a smaller number of osteoclasts in the well (RANKL + grape powder extract) as compared to image B (RANKL only) which reflects higher number of osteoclasts. 


\subsection{In-vivo}

The aim of the in-vivo experiments was to elucidate the role of grape powder as a means to reduce gingival inflammation and bone loss. A murine ligature-induced and baker model was used to closely mimic periodontitis.

\subsubsection{GRAPE POWDER TREATMENT DOWNREGULATES THE EXPRESSION OF PRO-INFLAMMATORY CYTOKINES IL-6 AND TNF- $\alpha$}

On the basis of the ability of the grape powder extract to inhibit inflammatory cytokine production as demonstrated by in-vitro experiments, we wanted to investigate the ability of grape powder to reduce inflammation in-vivo. Grape powder diet was specially formulated by California Table Grape Commission by adding 5\% grape powder extract to the regular mouse diet. Diet was prepared in accordance with calculating mouse body weight and average human consumption of grape by humans. We used a murine-ligatureinduced periodontitis model. 

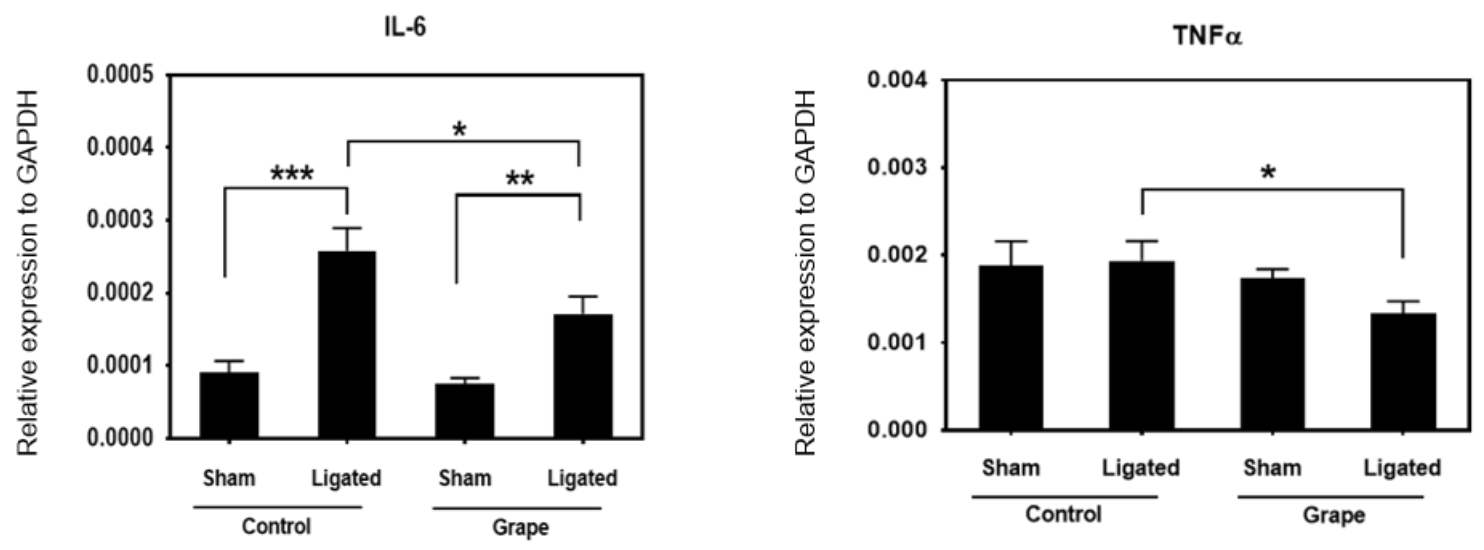

Figure 12. Comparison of gingival mRNA expression of IL-6 and TNF- $\alpha$ relative to internal control gene GAPDH in four different groups of mice.

1. Sham + Control (no ligation, no P. gingivalis infection, control diet), 2. Ligated + Control (Ligation $+P$. gingivalis infection + Control diet), 3. Sham + grape - grape powder diet, 4 . Ligated + grape (ligation $+P$. gingivalis infection + grape powder diet). Gingival mRNA expression of IL-6 and TNF- $\alpha$ was determined using Quantitative realtime PCR. Asterisks indicate statistically significant differences $\left({ }^{*}, \mathrm{p}<0.05 ;{ }^{* *}, \mathrm{p}<0.01\right)$ between the labelled groups. Data were evaluated by two tailed t test.

Gingival expression of IL-6 and TNF- $\alpha$ was determined by using Quantitative real-time PCR in four different groups of mice; 1. Mice without periodontitis induction and fed with control diet (Sham + Control; no ligation, no $P$. gingivalis infection, control diet), 2 . Mice with periodontitis induction and fed with control diet (Ligated + Control; ligation + P. gingivalis infection + control diet), 3. Mice without periodontitis induction and fed with grape powder diet (Sham + Grape; no ligation, no $P$. gingivalis infection, grape powder diet, and 4. Mice with periodontitis induction and fed with grape powder diet (Ligated + Grape; ligation with $P$. gingivalis infection, grape powder diet). Maxillary 
gingiva was harvested and gingival mRNA expression for the indicated cytokines was measured using qPCR which was normalized against GAPDH (internal control) mRNA levels.

Group 1 mice (Sham + Control) and group 3 (Sham + Grape) showed minimal IL-6 expression, since they did not go through periodontitis induction. This indicates that grape powder did not cause inflammation on its own. Ligation with $P$. gingivalis infection induced significantly higher IL-6 expression in Group 2 mice (Ligated + Control) and Group 4 mice (Ligated + Grape), compared with their respective counterparts without ligation nor P. gingivalis infection (Sham + Control and Sham + Grape). Group 4 (Ligated + Grape) mice show significantly lower expression of IL-6 as compared to group 2 mice (Ligated + Control), indicating that grape consumption reduced IL-6 expression. Although there is a difference in IL-6 expression between Group 2 (Ligated + Control) and group 3 (Sham + Grape), it is not of our interests in this project and hence has not been compared for statistical significance.

Our results showed that grape consumption induced lower TNF- $\alpha$ expression, since Group 4 (Ligated + Grape) mice show significantly lower expression of TNF- $\alpha$ comparing with group 2 mice (Ligated + Control).

On the basis of this data we concluded that grape consumption significantly reduces the expression of IL-6 and TNF- $\alpha$. 

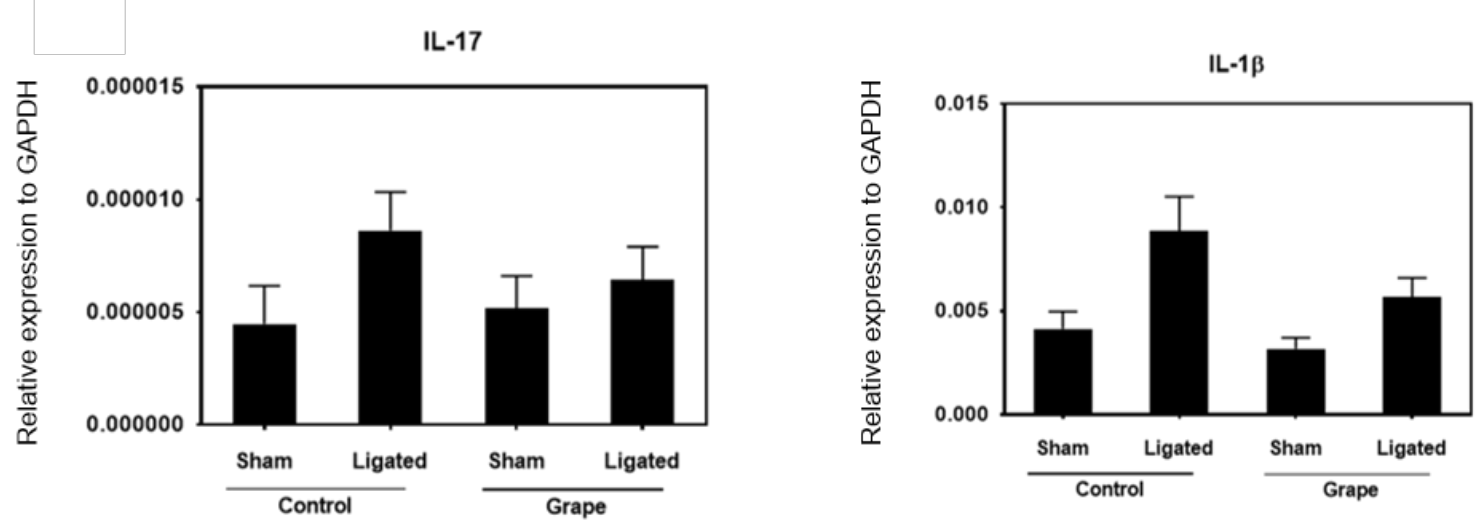

Figure 13. Comparison of gingival mRNA expression of IL-17 and IL-1 $\beta$ relative to internal control gene GAPDH in four different groups of mice.

1. Sham + Control (no ligation, no $P$. gingivalis infection, control diet), 2. Ligated + Control (ligation $+P$. gingivalis infection + control diet), 3. Sham + Grape - grape powder diet, 4. Ligated + Grape (ligation $+P$. gingivalis infection + grape powder diet). Gingival mRNA expression of IL-17 and IL-1 $\beta$ was determined using Quantitative realtime PCR. Data were evaluated by two tailed t test.

We further tested the IL-17 and IL-1 $\beta$ expression in gingival tissues. Although we observed the similar trend to IL-6 expression, there are no significant difference between the different groups. Our data did not show that grape powder inhibited the expression of IL-17 and IL-1 $\beta$. 

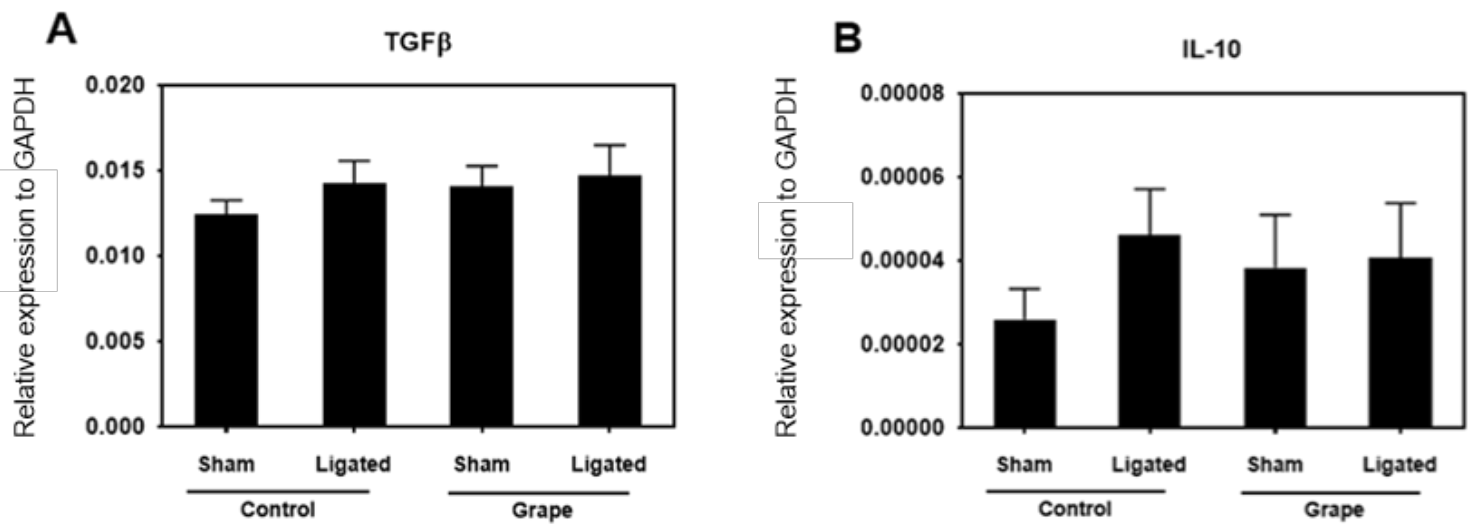

Figure 14. Comparison of gingival mRNA expression of anti-inflammatory cytokines TGF- $\beta$ and IL-10 relative to internal control gene GAPDH in four different groups of mice

1. Sham + Control (no ligation, no $P$. gingivalis infection, control diet), 2. Ligated + Control (ligation $+P$. gingivalis infection + control diet), 3. Sham + Grape - grape powder diet, 4. Ligated + Grape (ligation $+P$. gingivalis infection + grape powder diet) using Quantitative real-time PCR. Data were evaluated by two tailed t test.

TGF- $\beta$ and IL-10 are anti-inflammatory cytokines. We were interested in studying the expression of anti-inflammatory cytokines in the gingival tissues of mice that consumed the grape powder diet. We found no significant differences in the expression of TGF- $\beta$ and IL-10 between the groups. Our data implied that the grape consumption did not affect the expression of anti-inflammatory cytokines TGF- $\beta$ and IL-10.

Overall, our results indicate that grape powder is able to inhibit gingival inflammation in a murine ligature-induced periodontitis model. 


\subsubsection{GRAPE POWDER INHIBITS ALVEOLAR BONE LOSS IN A MURINE BAKER MODEL}

Our in-vitro experiments have already demonstrated that grape powder extract when treated with mouse monocytes stimulated with RANKL is able to inhibit their differentiation into osteoclasts. We were thus interested to highlight the role of grape powder in reducing alveolar bone loss in a murine model. A baker model was used for this purpose. Mice consumed a diet fortified with grape powder (regular mouse food + $5 \%$ grape powder). 

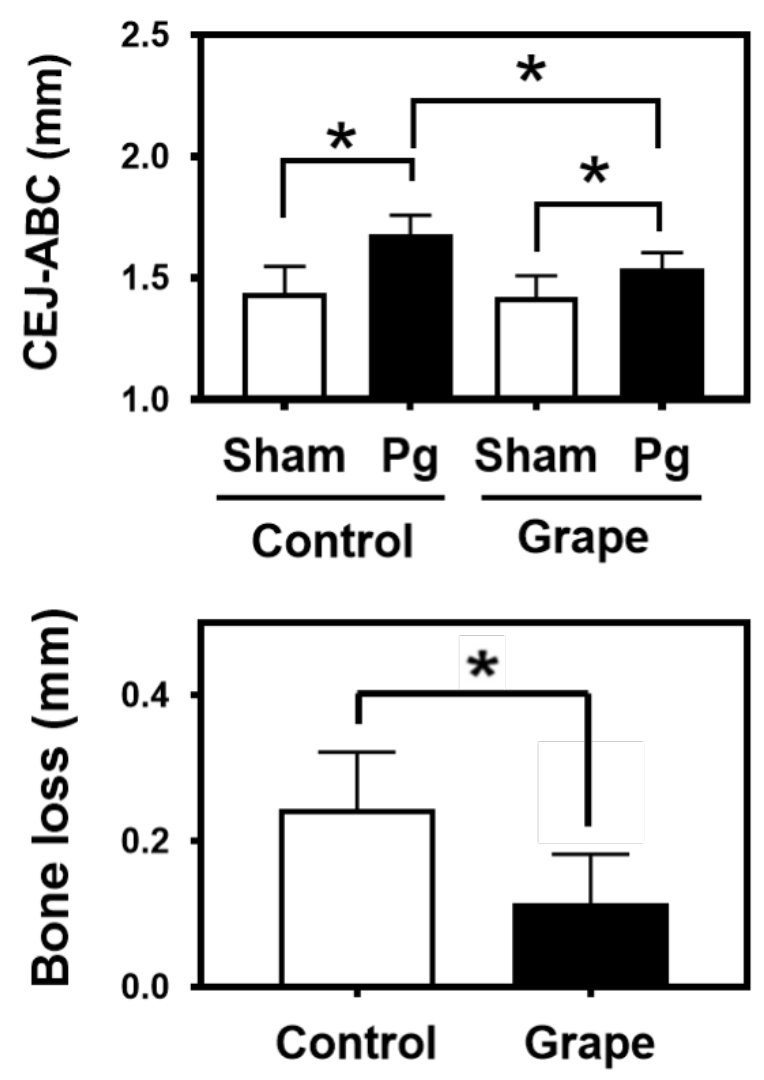

Figure 15. Comparison of CEJ-ABC distance and bone loss between different groups of mice.

1. Sham + Control (no P. gingivalis infection + control diet), 2. P. gingivalis control $(P$. gingivalis infection + control diet), 3. Sham + Grape (grape powder diet), 4. P. gingivalis + Grape $(P$. gingivalis infection + grape powder diet). Asterisks indicate statistically significant differences $(*, \mathrm{p}<0.05)$ between the labelled groups. Data were evaluated by two tailed t test.

Group 2 and group 4 BALB/c white mice were orally infected with $P$. gingivalis 5 times a day for 8 days around the maxillary molars and then kept for a period of 2 months to induce periodontitis. Group 1 and group 2 consumed a no grape powder (control) diet and 
group 3 and 4 consumed a grape powder diet (regular mouse diet fortified with 5\% grape powder extract). The distance from the cemento-enamel junction (CEJ) to the alveolar bone crest $(\mathrm{ABC})$ was measured at 14 predetermined sites on the maxillae and the mean for each mouse was calculated. Bone loss in the baker model was calculated by subtracting the fourteen-site total CEJ-ABC distance of group Sham + Control from group $P$. gingivalis + Control and group Sham + Grape from group P. gingivalis + Grape.

In Fig. 15., Group 1 (Sham mice) i.e. mice with no $P$. gingivalis infection and control diet and group 3 (Sham + Grape) i.e. mice who consumed only grape powder diet showed minimal CEJ-ABC distance. This indicates that grape powder did not cause bone loss on its own. Group 2 ( $P$. gingivalis + Control) had maximum CEJ-ABC distance which was significantly higher than group $1($ Sham + Control) and group $4(P$. gingivalis + Grape) Group 4 (P. gingivalis + Grape) showed significantly higher CEJ-ABC distance than group 3 (Sham + Grape). Although group 3 (Sham + Grape) shows reduced CEJ-ABC distance as compared to group 2 ( $P$. gingivalis + Control), these groups are not related and hence not compared for statistical significance. Bone loss was calculated as described above. There is significant reduction in bone loss in the group of mice that consumed grape powder diet as compared to control group of mice that consumed a control (no grape powder) diet. This data indicates that grape powder inhibits alveolar bone loss in a murine baker model. 


\section{CHAPTER 4. DISCUSSION}

Periodontitis is a chronic, multifactorial inflammatory disease of infectious nature which leads to destruction of the tissues supporting the tooth. The interaction between bacteria lodged in the dental biofilm and immune response of the host decisively affects the progression and clinical signs of periodontal disease (Kaur, Grover et al. 2018). $P$. gingivalis, a Gram-negative, anaerobic bacterium, has been studied extensively as one member of the microbiota involved in periodontal disease progression and subsequent bone and tissue destruction (Holt, Kesavalu et al. 1999). P. gingivalis is well known for its function to regulate host immunity and induce oral microbiota dysbiosis, therefore causing inflammation and collateral tissue damage (Rafiei, Kiani et al. 2017). According to data published by the third US National Health and Nutrition Examination Survey, antibody titers against $P$. gingivalis were located in the periodontal pockets of a large adult population (Dye, Herrera-Abreu et al. 2009). This aroused our interest in studying $P$. gingivalis as part of the in vitro experiments in the context of being an inducer of chronic periodontitis.

Studies have also reported that fruit and vegetable consumption is associated with a reduced risk of various diseases (Nanri, Yamada et al. 2017). The focus of our study was to examine the possible favorable or detrimental effect of grape and its components on periodontal disease. Among a number of potential oral health promoting fruits, the grape was selected as our fruit of interest for several reasons. The fact that humans have been 
using grape and grape wine products since centuries for not only food purposes but also several medicinal purposes (Ali, Maltese et al. 2010) and their extensive application in the wine and juice industry (Torregrosa, Bigard et al. 2017) sparked our interest in this unique fruit. Grapes are rich in several components which belong to a large family of compounds called Flavonoids which are further divided into smaller components like catechins and pro-anthocyanidins (de la Iglesia, Milagro et al. 2010). There has been extensive research on specific grape components which paved the way to the rationale for our study. Pro-anthocyanidins inhibit biofilm formation and adhesion of oral bacteria, proteolytic activities of bacteria and cytokine production by immune cells (Bonifait and Grenier 2010). Catechin has a bactericidal effect against gram-negative rods (Hirasawa, Takada et al. 2002) and also suppresses genes associated with biofilm formation (Xu, Zhou et al. 2012). Considering these previous studies and their results, we decided to take a step further and thus studied the effect of whole grapes on bacterial growth, osteoclastogenesis and inflammation in vitro and inflammation and bone loss in vivo.

There have been extensive studies testing the effect of different forms of grape - grape seed extract, grape seed pro-anthocyanidins, catechin, epicatechin etc. on bacteria and inflammation. Our study was unique in a way that we used grape powder extract and grape powder of whole grapes obtained from the California Table Grape Commission for the in vitro and in vivo experiments respectively. We hypothesized that the grape powder extract can inhibit $P$. gingivalis growth, and directly prevent osteoclastogenesis and proinflammatory cytokines production in vitro. We also hypothesized that this grape powder inhibits gingival inflammation and prevents bone loss in a murine model for periodontitis. 
Grape powder extract used in the in vitro experiments was formulated in an organic solvent DMSO and not water after establishing that the grape powder extract was originally prepared in an organic solvent which rendered all its active and inactive components completely soluble. We observed a dose dependent reduction in the formation of $P$. gingivalis $\mathrm{CFU}$ after subsequent treatment with the grape powder extract. The bacteria were subjected to higher concentrations of grape powder extract than used in the other experiments, the highest being $0.5 \mathrm{mg} / \mathrm{ml}$ after which we observed the highest reduction in $P$. gingivalis CFU. Using this concentration, although not falling in the physiological range was justified by the fact that higher concentrations were required to kill or inhibit the growth of oral bacteria. Also in a previous research studying the effect of grape seed pro-anthocyanidins on $P$. gingivalis LPS, the minimum inhibitory concentration of pro-anthocyanidins was established to be $0.8 \mathrm{mg} / \mathrm{ml}(\mathrm{Ci}$, Chen et al. 2015). We could expand our knowledge on this topic by testing the effect of grape powder extract on the growth of other bacteria associated with the pathogenesis of periodontal disease like Aggregatibacter actinomycetemcomitans. Considering the current PSD model and its emphasis on periodontal disease being caused as an outcome of dysbiosis rather than select bacteria (Hajishengallis and Lamont 2012), we could study the effect of grape powder extract on oral microbiota. To that effect we could detect the disease specific bacteria by employing RNA-Seq (RNA sequencing) to find out which bacteria are more prevalent in the oral cavity and target those with our grape powder extract.

Periodontal disease is a consequence of chronic inflammation in which pro-inflammatory cytokines play a central role. Grape components like pro-anthocyanidins, catechin and 
epicatechin possess strong anti-inflammatory properties (Gu, Kelm et al. 2004). Proanthocyanidins from cranberries downregulated the expression of IL-6 and IL-8 in gingival fibroblasts stimulated with LPS from select periopathogens like $P$. ginigivalis, $A$. actinomycetemcomitans and T. denticola (Bodet, Grenier et al. 2008). To that effect, we studied the expression of IL-6 as an outcome of $P$. gingivalis LPS induced stimulation with prior grape powder extract treatment. We chose LPS over other stimulants due its easy availability and stable lipid nature. Concentration of $1 \mu \mathrm{g} / \mathrm{ml}$ LPS was decided after considering previous literature and having been tried and tested to achieve a good meaningful signal for IL-6 expression. From our experiment we learned that grape powder extract could inhibit $P$. gingivalis LPS induced IL-6 expression in RAW 264.7 cells. Our grape powder extract was prepared in DMSO which is known to be inhibitory as higher concentrations. As we used high concentrations of DMSO $(25,50,100 \mu \mathrm{g} / \mathrm{ml})$ corresponding to our grape extract concentrations, we also eliminated the possibility of DMSO interfering in the downregulation of IL-6. In future, the grape powder extract could be tested on many more pro-inflammatory cytokines related to periodontal disease like IL-17.

The NF-kB signaling pathway plays a crucial role in inflammation and immune responses for being at the crossroad of various signaling pathways. Several researchers have described the role of NF- $\mathrm{kB}$ as "good" when regulating immunological functions and "evil" when it is dysregulated (Pahl 1999). Although prolonged or imbalanced activation of NF-kB genes generates chronic inflammation, this inflammatory program may be mediated without potentially damaging the host cells (Barkett and Gilmore 1999) which works in favor of the "good" theory. P. gingivalis LPS induces production of pro- 
inflammatory cytokines and osteoclastogenesis through NF-kB signaling which in turn causes periodontal tissue destruction (Choi, Moon et. al 2005). Researchers have attempted to block this pathway at various steps with natural biomolecules.

We were thus interested in studying the level of involvement of NF- $\mathrm{kB}$ signaling in an attempt to study the possible mechanism of grape powder extract. Our results indicated that there was a dose dependent reduction in NF- $\mathrm{kB}$ signaling after being subjected to grape powder extract. However, the concentration of LPS used to elicit the positive control was ten times higher than used in our previous experiments. The reason for this may be traced back to the weak nature of the LPS as an agonist and also indicate a potential limitation of this assay. In contrast to our previous experiments, the concentration of DMSO used to prepare the grape powder extract was similar in all dosages and thus we did not require DMSO as a separate control. Our data reflected the NF- $\mathrm{B}$ signaling activity at a one-hour time point which provided us meaningful inhibition by grape powder extract. We used THP1-Blue cells ${ }^{\mathrm{TM}}$ to study NF-kB signaling activity due to the presence of NF-kB-inducible SEAP (secreted embryonic alkaline phosphatase) reporter construct. The exact mechanism by which these grape components exhibit these anti-inflammatory properties still remains an area of debate. NF-kB plays an important pathogenic role in periodontitis (Arabaci, Cicek et al. 2010) (Pacios, Xiao et al. 2015). Under normal conditions, in response to an infection, NF- $\mathrm{kB}$ is sequestered in the cytoplasm as an inactive complex with the inhibitory protein IкB. Upon stimulation, IкB is phosphorylated, ubiquitinated and degraded. Consequently, NF$\kappa \mathrm{B}$ becomes free to translocate to the nucleus where it initiates the expression of NF- $\mathrm{KB}$ dependent pro-inflammatory cytokines, osteoclastogenesis and bone loss (Zhou, Su et al. 
2018). Inhibition of NF-kB translocation is possible through several mechanisms, a few of which are a) inhibition of IKK complex, b) interfering with the translocation of NF-kB to the nucleus. An experiment conducted by a group of researchers concluded that grape components were able to decrease the phosphorylation of IKKa/b which suggested that the anti-inflammatory action of grape components could at least partially be due to inhibition of the NF-kB dependent gene transcription (Chu, Tang et al. 2016). Our experiment also suggested the involvement of NF- $\mathrm{KB}$ signaling pathway. Additionally, some other studies have also reported the involvement of MAP kinases and AkT signaling pathways as potential targets for grape components (Lee, Kim et al. 2017). Future studies could be directed at studying if and how the effects of grape powder extract are mediated through these pathways.

Harmony between osteoblastic and osteoclastic activity is detrimental for maintaining an ideal bone homeostasis (Tanaka, Nakayamada et al. 2005). Imbalance in this activity favors osteoclastogenesis or bone resorption which is a characteristic feature of periodontitis mediated through the NF-kB signaling pathway (Takayanagi, Iizuka et al. 2000). According to a study by Nakagawa and Yokozawa in 2002, catechin was able to inhibit formation of osteoclasts from precursor cells (Nakagawa and Yokozawa 2002). Similarly, we decided to investigate if our grape powder extract had an effect on the osteoclast forming ability of RAW 264.7 cells. Based on the results obtained from our previous experiment on NF- $\mathrm{KB}$ signaling, a single effective concentration of $200 \mu \mathrm{g} / \mathrm{ml}$ of grape powder extract was chosen and we established that grape powder extract was clearly interfering in the osteoclast forming ability of RAW 264.7 cells after treatment with RANKL. We may like to experiment with different concentrations of grape powder 
extract in future and also test the effect of different grape components like catechin on osteoclast formation and differentiation.

The anti-inflammatory properties of grape powder extract have already been highlighted through our previous experiments. According to previous literature, grape seed extract in the diet of laboratory mice reduced inflammatory cell number (ICN), connective tissue attachment level (CAL), osteoclast density (OD), and higher IL-10 and TGF- $\beta$ expression in ligature induced periodontitis model (Özden, Sakallioğlu et al. 2017). We decided to take our research a step further by investigating the effects of grape powder extract in vivo. To achieve this, we used a murine ligature-induced model. This model allows for a stronger and intense inflammation in a shorter time period (Abe and Hajishengallis 2013) so it was specifically chosen to study inflammation through studying the expression of some important pro-inflammatory cytokines - IL-6, TNF- $\alpha$, IL-17 and IL-1 $\beta$ and antiinflammatory cytokines IL-10 and TGF- $\beta$. These cytokines were selected on the basis of previous literature as the most potent in relation to periodontal disease. The ligated mice were also infected with $P$. gingivalis to accelerate the periodontal disease process. Similar to previous literature, select mice groups consumed a diet fortified with grape powder (5\%) which was specially formulated by the California Table Grape Commission. The mice from control groups consumed a low fat control diet without added grape powder. Our data reflected that grape powder extract was able to significantly downregulate the expression of pro-inflammatory cytokines IL-6 and TNF- $\alpha$ (Fig 12). However, there was no significant effect on IL-17 and IL-1 $\beta$ expression in spite of having a reduced trend as compared to our positive controls (Fig 13). This might reflect 2 things - 1. IL-17 and IL$1 \beta$ are not as critical as IL-6 and TNF- $\alpha$ in the inflammatory process 2 . Operator error 
while performing the assay. Although group 4 mice (ligation $+P$. gingivalis infection + grape powder diet) showed higher expression of TGF- $\beta$ as compared to group 2 mice (ligation $+P$. gingivalis infection + control diet), the differences were not significant. Also, the expression of IL-10 was not altered in the group 4 mice (Fig 14). Antiinflammatory cytokines are part of a feedback protective mechanism in humans and animals that try and resolve the inflammation initiated by pro-inflammatory cytokines which was clearly indicated by TGF- $\beta$ levels in group 4 mice. We were of the opinion that the grape powder might elicit intense protective mechanism in response to inflammation which was also highlighted by previous research (Özden, Sakallioğlu et al. 2017). However, our data did not reflect that. This might indicate that anti-inflammatory response is not the main target of the grape components or technical errors from our side. At present, our data suggests that grape components are able to reduce inflammation by targeting select pro-inflammatory cytokines. However, these cytokines may still need to be investigated further in depth. Bone loss was studied in the ligature model; however we did not expect to see results due to the short duration of this model and potential inability of the grape powder to elicit positive results in this short time period. Our results reflected the same (data not shown). We might expect to see better results in future by designing the experiment in a way as to pre-feed the mice with grape powder diet for a period of 2 months before ligation and infection with P. gingivalis. Another way may be to increase the dose of grape powder in the diet.

The Baker model was chosen to study bone loss since it a better representation of the chronic nature of periodontitis and allows adequate time for colonization of bacteria. Previous research has reported that grape seed pro-anthocyanidins contribute to bone 
homeostasis by increasing mandibular bone formation and bone strength (Kamitani, Maki et al. 2004). Another study evaluated the effect of grape seed pro-anthocyanidins on alveolar bone loss in mice and found reduced inflammation and bone loss via decreased MMP-8 levels and increased osteoblastic activity (Toker, Balci Yuce et al. 2018). These previous studies provided us a good rationale for investigating the effect of grape powder on alveolar bone loss. Since the orally infected $P$. gingivalis equally colonizes the whole oral cavity in a period of 2 months, we expected to see higher bone loss levels and thus bone loss was measured at 14 predetermined sites. Buccal bone being thin and fenestrated was chosen as ideal to study bone loss. Our data confirmed that grape powder had a positive impact on alveolar bone as indicated by reduced CEJ-ABC distance and bone loss levels (Fig 15).

Some researchers were particularly concerned about the detrimental effects of grape components on RAW 264.7 cells. An experiment to assess the cytotoxicity of grape seed pro-anthocyanidins was measured by MTT assay which concluded that RAW 264.7 cell viability was not affected significantly by using concentrations up to $200 \mu \mathrm{g} / \mathrm{ml}$ (Chu, Tang et al. 2016). This explains the basis for using the chosen concentrations of grape powder extract in our research. An oral toxicity study of pro-anthocyanidins in the grape skin and grape seed extract was conducted in mice over a three-month period, which revealed no changes considered to be of toxicological significance (Bentivegna and Whitney 2002). Thus, grape components may be developed as safe drugs for treatment of periodontal disease.

The experimental findings in this research suggest that grape and its components could be a promising natural agent for preventive and therapeutic treatment of periodontitis. Grape 
and grape components show great potential in periodontitis therapy on account of their anti-bacterial, anti-inflammatory and anti-oxidative properties and ability to directly inhibit osteoclastogenesis (Kempuraj, Madhappan et al. 2005). Our grape powder extract is novel in the sense that this type of extract produced from whole grapes has not been used in previous research. Grape powder extract has active and inactive components. These components have been filtered according to their molecular weight fractions and the most active components have been recognized. These are catechin, epicatechin, quercetin, malvidin and peonidin. Future studies could be directed at testing the effects of these specific active components on $P$. gingivalis growth, inflammation and bone loss. It would be rewarding to find a single component exhibiting antibacterial properties specific to $P$. gingivalis in conjunction with anti-inflammatory effects. The mechanism of how our grape powder extract interacts with $P$. gingivalis still remains an area of discussion. Grape components might possess antiadhesive properties which interfere with the biofilm formation of $P$. gingivalis as previously seen with the ability of grape components to inhibit biofilms of Streptococcus mutans (de la Iglesia, Milagro et al. 2010). Another study has also reported that pro-anthocyanidins from cranberries could inhibit $P$. gingivalis biofilm formation (Labrecque, Bodet et al. 2006). We argued if the mild acidic nature of grape powder extract was itself responsible for affecting $P$. gingivalis growth. However, this seems unlikely since the acidity would have been neutralized by the buffers present in the culture media. Another theory for this interaction could be the presence of receptors on the surface of $P$. gingivalis which interact with antibiotics in the grape components. One study by a group of researchers established that black grape skin extract is rich in antimicrobial compounds which inhibit the growth of 
certain bacteria (Yadav, Kumar et al. 2015). This seems like a reasonable explanation for our question.

It would seem beneficial to control periodontal inflammation by implementing pharmacological adjuncts in addition to conventional mechanical therapy. One popular approach for improving periodontal health is the use of therapeutic agents in oral hygiene products (Ciancio 2011). Adding active components to toothpastes or mouthwashes may enhance plaque removal. Grape power extract may be tested in dentifrices in this context. Topical application may be another method to consider. Green tea catechin when applied in the form of hydroxypropycellulose strips in the pockets of periodontal patients exhibited an anti-bacterial affect against $P$. gingivalis and $P$. intermedia (Hirasawa, Takada et al. 2002). It may be necessary to conduct further preclinical animal and human trial studies as to gauge in what combinations and formulations these grape components when used will be most effective in controlling periodontal inflammation (Palaska, Papathanasiou et al. 2013). We can take our research a step further by experimenting with human trial studies. One approach to testing the effect of grape powder extract in humans would be to conduct experimental gingivitis studies with appropriate placebo controls. The grape powder extract could be delivered in an injectable form or through a chewing gum and the levels of inflammation and bacterial growth could be assessed after a certain time period.

Oral diseases like caries and periodontal disease resulting in pain and tooth loss are one of the commonly prevailing conditions that affect the American population (Bennadi and Reddy 2013). These oral diseases not only impact systemic health but overall physical, psychological, social, and economic well-being (Murthy 2016). Much recently, attention 
of researchers has been focused on identification of fruit components and development of natural food products as "functional foods". In spite of these advances, it seems that people are still less aware of specific fruits that play a role in maintaining good oral health and need to be brought to public attention. Naturally occurring active components in fruits like grape have been shown to promote periodontal health. Our research successfully attempted to investigate the grape in the context of causing good or harm to periodontal health. We were able to establish that grape and its components were a safe and natural means to control periodontal inflammation. Our research highlights that grapes should be included as an important component of diet to promote oral health in a natural way without any significant adverse effects. On the basis of this research and further studies, we may find grape-derived compounds as alternatives or replacement to the routinely used chemicals implicated in mechanical oral disease control in future. On the basis of existing data, it is evident that grapes should be considered as an inherent element of fruit-enriched diets that are encouraged strongly by health authorities worldwide as a rewarding natural means to stay healthy and prevent disease. It is also noteworthy that for the vast majority of people consuming grapes, allergy to this fruit is hardly an issue (Pezzuto 2008). Also, who doesn't like grapes?

In summary, our experimental results have successfully proven that grape components are capable of inhibiting $P$. gingivalis growth, reducing pro-inflammatory cytokine production, and RANKL-induced osteoclastogenesis. In addition, grape components are able to reduce gingival inflammation and alveolar bone loss in murine models. On the basis of these results, we can conclude that grape and grape components can indeed be beneficial in the prevention and treatment of periodontal disease. 


\section{REFERENCES}

1. Abe, T. and G. Hajishengallis (2013). "Optimization of the ligature-induced periodontitis model in mice." Journal of immunological methods 394(1-2): 49-54.

2. Abe, T. and G. Hajishengallis (2013). "Optimization of the ligature-induced periodontitis model in mice." J Immunol Methods 394(1-2): 49-54.

3. Abusleme, L., A. K. Dupuy, N. Dutzan, N. Silva, J. A. Burleson, L. D. Strausbaugh, J. Gamonal and P. I. Diaz (2013). "The subgingival microbiome in health and periodontitis and its relationship with community biomass and inflammation." Isme j 7(5): 1016-1025.

4. Ahmad, N., S. Gupta and H. Mukhtar (2000). "Green tea polyphenol epigallocatechin-3-gallate differentially modulates nuclear factor kappaB in cancer cells versus normal cells." Arch Biochem Biophys 376(2): 338-346.

5. Ali, K., F. Maltese, Y. H. Choi and R. Verpoorte (2010). "Metabolic constituents of grapevine and grape-derived products." Phytochemistry reviews : proceedings of the Phytochemical Society of Europe 9(3): 357-378.

6. Arabaci, T., Y. Cicek, V. Canakci, C. F. Canakci, M. Ozgoz, M. Albayrak and O. N. Keles (2010). "Immunohistochemical and Stereologic Analysis of NF-кB Activation in Chronic Periodontitis." European journal of dentistry 4(4): 454-461.

7. Aruni, A. W., Y. Dou, A. Mishra and H. M. Fletcher (2015). "The Biofilm Community-Rebels with a Cause." Current oral health reports 2(1): 48-56. 
8. Bagchi, D., C. K. Sen, S. D. Ray, D. K. Das, M. Bagchi, H. G. Preuss and J. A. Vinson (2003). "Molecular mechanisms of cardioprotection by a novel grape seed proanthocyanidin extract." Mutat Res 523-524: 87-97.

9. Baker, P. J., M. Dixon and D. C. Roopenian (2000). "Genetic control of susceptibility to Porphyromonas gingivalis-induced alveolar bone loss in mice." Infection and immunity 68(10): 5864-5868.

10. Baker, P. J., R. T. Evans and D. C. Roopenian (1994). "Oral infection with Porphyromonas gingivalis and induced alveolar bone loss in immunocompetent and severe combined immunodeficient mice." Arch Oral Biol 39(12): 1035-1040.

11. Barkett, M. and T. D. Gilmore (1999). "Control of apoptosis by Rel/NF-kappaB transcription factors." Oncogene 18(49): 6910-6924.

12. Barnes, P. J. and M. Karin (1997). "Nuclear factor- $\kappa B-a$ pivotal transcription factor in chronic inflammatory diseases." New England Journal of Medicine 336(15): 1066-1071.

13. Beinke, S., M. P. Belich and S. C. Ley (2002). "The death domain of NF-kappa B1 p105 is essential for signal-induced p105 proteolysis." J Biol Chem 277(27): 24162-24168.

14. Bennadi, D. and C. V. K. Reddy (2013). "Oral health related quality of life." Journal of International Society of Preventive \& Community Dentistry 3(1): 1-6.

15. Bentivegna, S. S. and K. M. Whitney (2002). "Subchronic 3-month oral toxicity study of grape seed and grape skin extracts." Food Chem Toxicol 40(12): 17311743. 
16. Bergstrom, J. (2006). "Periodontitis and smoking: an evidence-based appraisal." J Evid Based Dent Pract 6(1): 33-41.

17. Bertolini, A., A. Ottani and M. Sandrini (2002). "Selective COX-2 inhibitors and dual acting anti-inflammatory drugs: critical remarks." Curr Med Chem 9(10): 1033-1043.

18. Bertolini, D. R., G. E. Nedwin, T. S. Bringman, D. D. Smith and G. R. Mundy (1986). "Stimulation of bone resorption and inhibition of bone formation in vitro by human tumour necrosis factors." Nature 319: 516.

19. Bezerra, M. M., V. de Lima, V. B. Alencar, I. B. Vieira, G. A. Brito, R. A. Ribeiro and F. A. Rocha (2000). "Selective cyclooxygenase-2 inhibition prevents alveolar bone loss in experimental periodontitis in rats." J Periodontol 71(6): 1009-1014.

20. Blignaught, J. and S. Grobler (1992). "High fruit consumption and the periodontal status of farm workers." Clinical Preventive Dentistry 14(2): 25-28.

21. Bodet, C., D. Grenier, F. Chandad, I. Ofek, D. Steinberg and E. I. Weiss (2008). "Potential Oral Health Benefits of Cranberry." Critical Reviews in Food Science and Nutrition 48(7): 672-680.

22. Bonifait, L. and D. Grenier (2010). "Cranberry polyphenols: potential benefits for dental caries and periodontal disease." J Can Dent Assoc 76: a130.

23. Boyce, B. F. (2013). "Advances in osteoclast biology reveal potential new drug targets and new roles for osteoclasts." J Bone Miner Res 28(4): 711-722.

24. Boyce, B. F. and L. Xing (2007). "The RANKL/RANK/OPG pathway." Osteoporos Rep 5(3): 98-104. 
25. Cassai, E., M. Galvan, L. Trombelli and A. Rotola (2003). "HHV-6, HHV-7, HHV-8 in gingival biopsies from chronic adult periodontitis patients. A casecontrol study." J Clin Periodontol 30(3): 184-191.

26. Chabaud, M., F. Fossiez, J. L. Taupin and P. Miossec (1998). "Enhancing effect of IL-17 on IL-1-induced IL-6 and leukemia inhibitory factor production by rheumatoid arthritis synoviocytes and its regulation by Th2 cytokines." J Immunol 161(1): 409-414.

27. Chabaud, M. and P. Miossec (2001). "The combination of tumor necrosis factor alpha blockade with interleukin-1 and interleukin-17 blockade is more effective for controlling synovial inflammation and bone resorption in an ex vivo model." Arthritis Rheum 44(6): 1293-1303.

28. Chen, F. E. and G. Ghosh (1999). "Regulation of DNA binding by Rel/NFkappaB transcription factors: structural views." Oncogene 18(49): 6845-6852.

29. Choi, B. K., S. Y. Moon, J. H. Cha, K. W. Kim and Y. J. Yoo (2005). "Prostaglandin E(2) is a main mediator in receptor activator of nuclear factorkappaB ligand-dependent osteoclastogenesis induced by Porphyromonas gingivalis, Treponema denticola, and Treponema socranskii." J Periodontol 76(5): 813-820.

30. Chu, H., Q. Tang, H. Huang, W. Hao and X. Wei (2016). "Grape-seed proanthocyanidins inhibit the lipopolysaccharide-induced inflammatory mediator expression in RAW264.7 macrophages by suppressing MAPK and NF-kappab signal pathways." Environ Toxicol Pharmacol 41: 159-166. 
31. Chu, H., Q. Tang, H. Huang, W. Hao and X. Wei (2016). "Grape-seed proanthocyanidins inhibit the lipopolysaccharide-induced inflammatory mediator expression in RAW264.7 macrophages by suppressing MAPK and NF-кb signal pathways." Environmental Toxicology and Pharmacology 41: 159-166.

32. Ci, X. K., L. P. Chen and X. Y. Ou (2015). "[Grape seed proanthocyanidin extracts inhibit lipopolysaccharide of Porphyromonas gingivalis]." Shanghai Kou Qiang Yi Xue 24(4): 433-436.

33. Ciaccia, L. (2011). "Fundamentals of Inflammation." The Yale Journal of Biology and Medicine 84(1): 64-65.

34. Ciancio, S. G. (2011). "Controlling biofilm with evidence-based dentifrices." Compend Contin Educ Dent 32(1): 70-76.

35. Coats, S. R., R. A. Reife, B. W. Bainbridge, T.-T. T. Pham and R. P. Darveau (2003). "Porphyromonas gingivalis Lipopolysaccharide Antagonizes Escherichia coli Lipopolysaccharide at Toll-Like Receptor 4 in Human Endothelial Cells." Infection and Immunity 71(12): 6799-6807.

36. Darveau, R. P., S. Arbabi, I. Garcia, B. Bainbridge and R. V. Maier (2002). " $<$ em $>$ Porphyromonas gingivalis $</$ em $>$ Lipopolysaccharide Is Both Agonist and Antagonist for p38 Mitogen-Activated Protein Kinase Activation." 70(4): 18671873.

37. Darveau, R. P., T.-T. T. Pham, K. Lemley, R. A. Reife, B. W. Bainbridge, S. R. Coats, W. N. Howald, S. S. Way and A. M. Hajjar (2004). "Porphyromonas gingivalis lipopolysaccharide contains multiple lipid A species that functionally 
interact with both toll-like receptors 2 and 4." Infection and immunity 72(9): 5041-5051.

38. de la Iglesia, R., F. I. Milagro, J. Campion, N. Boque and J. A. Martinez (2010). "Healthy properties of proanthocyanidins." Biofactors 36(3): 159-168.

39. Dewhirst, F. E., T. Chen, J. Izard, B. J. Paster, A. C. Tanner, W. H. Yu, A. Lakshmanan and W. G. Wade (2010). "The human oral microbiome." J Bacteriol 192(19): 5002-5017.

40. Di Benedetto, A., I. Gigante, S. Colucci and M. Grano (2013). "Periodontal Disease: Linking the Primary Inflammation to Bone Loss." Clinical and Developmental Immunology 2013: 7.

41. Dinarello, C. A. (1996). "Biologic basis for interleukin-1 in disease." Blood 87(6): 2095-2147.

42. Ding, P. H., R. P. Darveau, C. Y. Wang and L. Jin (2017). "3LPS-binding protein and its interactions with P. gingivalis LPS modulate pro-inflammatory response and Toll-like receptor signaling in human oral keratinocytes." PLoS One 12(4): e0173223.

43. Dye, B. A., M. Herrera-Abreu, J. Lerche-Sehm, C. Vlachojannis, L. Pikdoken, B. Pretzl, A. Schwartz and P. N. Papapanou (2009). "Serum antibodies to periodontal bacteria as diagnostic markers of periodontitis." J Periodontol 80(4): 634-647.

44. Eke, P. I., B. A. Dye, L. Wei, G. D. Slade, G. O. Thornton-Evans, W. S. Borgnakke, G. W. Taylor, R. C. Page, J. D. Beck and R. J. Genco (2015). "Update 
on Prevalence of Periodontitis in Adults in the United States: NHANES 2009 to 2012." Journal of periodontology 86(5): 611-622.

45. Feng, X. and J. M. McDonald (2011). "Disorders of Bone Remodeling." Annual review of pathology 6: 121-145.

46. Feno Al, S. R., Krishnan S (2014). "Levels of Interleukin -10 in Gingival Crevicular Fluid and its Role in the Initiation and Progression of Gingivitis to Periodontitis." J Oral Hyg Health 2.

47. Florencio-Silva, R., G. R. d. S. Sasso, E. Sasso-Cerri, Sim, \#xf5, M. J. es, P. S. Cerri, \#xe9 and rgio (2015). "Biology of Bone Tissue: Structure, Function, and Factors That Influence Bone Cells." BioMed Research International 2015: 17.

48. Gabetta, B., N. Fuzzati, A. Griffini, E. Lolla, R. Pace, T. Ruffilli and F. Peterlongo (2000). "Characterization of proanthocyanidins from grape seeds." Fitoterapia 71(2): 162-175.

49. Gaffen, S. L. (2008). "An overview of IL-17 function and signaling." Cytokine 43(3): 402-407.

50. Gao, L., T. Xu, G. Huang, S. Jiang, Y. Gu and F. Chen (2018). "Oral microbiomes: more and more importance in oral cavity and whole body." Protein \& Cell 9(5): 488-500.

51. Garlet, G. P. (2010). "Destructive and protective roles of cytokines in periodontitis: a re-appraisal from host defense and tissue destruction viewpoints." J Dent Res 89(12): 1349-1363.

52. Geng, F., J. Liu, Y. Guo, C. Li, H. Wang, H. Wang, H. Zhao and Y. Pan (2017). "Persistent Exposure to Porphyromonas gingivalis Promotes Proliferative and 
Invasion Capabilities, and Tumorigenic Properties of Human Immortalized Oral Epithelial Cells." Front Cell Infect Microbiol 7: 57.

53. Gilmore, T., M. E. Gapuzan, D. Kalaitzidis and D. Starczynowski (2002).

"Rel/NF-kappa B/I kappa B signal transduction in the generation and treatment of human cancer." Cancer Lett 181(1): 1-9.

54. Gokul, K., M. Faizuddin and A. R. Pradeep (2012). "Estimation of the level of tumor necrosis factor- alpha in gingival crevicular fluid and serum in periodontal health \& disease: A biochemical study." Indian J Dent Res 23(3): 348-352.

55. Gordon, J. I. and T. R. Klaenhammer (2011). "A rendezvous with our microbes." Proc Natl Acad Sci U S A 108 Suppl 1: 4513-4515.

56. Graves, D. T. and D. Cochran (2003). "The contribution of interleukin-1 and tumor necrosis factor to periodontal tissue destruction." J Periodontol 74(3): 391401.

57. Graves, D. T., D. Fine, Y.-T. A. Teng, T. E. Van Dyke and G. Hajishengallis (2008). "The use of rodent models to investigate host-bacteria interactions related to periodontal diseases." Journal of clinical periodontology 35(2): 89-105.

58. Gu, L., M. A. Kelm, J. F. Hammerstone, G. Beecher, J. Holden, D. Haytowitz, S. Gebhardt and R. L. Prior (2004). "Concentrations of proanthocyanidins in common foods and estimations of normal consumption." J Nutr 134(3): 613-617.

59. Hacker, H. and M. Karin (2006). "Regulation and function of IKK and IKKrelated kinases." Sci STKE 2006(357): re13.

60. Hajishengallis, G. (2014). "Immunomicrobial pathogenesis of periodontitis: keystones, pathobionts, and host response." Trends Immunol 35(1): 3-11. 
61. Hajishengallis, G. and R. J. Lamont (2012). "Beyond the red complex and into more complexity: the polymicrobial synergy and dysbiosis (PSD) model of periodontal disease etiology." Mol Oral Microbiol 27(6): 409-419.

62. Hajishengallis, G. and R. J. Lamont (2014). "Breaking bad: manipulation of the host response by Porphyromonas gingivalis." Eur J Immunol 44(2): 328-338.

63. Hajishengallis, G., S. Liang, M. A. Payne, A. Hashim, R. Jotwani, M. A. Eskan, M. L. McIntosh, A. Alsam, K. L. Kirkwood, J. D. Lambris, R. P. Darveau and M. A. Curtis (2011). "Low-abundance biofilm species orchestrates inflammatory periodontal disease through the commensal microbiota and complement." $\underline{\text { Cell }}$ Host Microbe 10(5): 497-506.

64. Halleen, J. M., S. L. Tiitinen, H. Ylipahkala, K. M. Fagerlund and H. K. Vaananen (2006). "Tartrate-resistant acid phosphatase 5b (TRACP 5b) as a marker of bone resorption." Clin Lab 52(9-10): 499-509.

65. Hanazawa, S., K. Nakada, Y. Ohmori, T. Miyoshi, S. Amano and S. Kitano (1985). "Functional role of interleukin 1 in periodontal disease: induction of interleukin 1 production by Bacteroides gingivalis lipopolysaccharide in peritoneal macrophages from $\mathrm{C} 3 \mathrm{H} / \mathrm{HeN}$ and $\mathrm{C} 3 \mathrm{H} / \mathrm{HeJ}$ mice." Infect Immun 50(1): $262-270$.

66. Hart, G. T., D. J. Shaffer, S. Akilesh, A. C. Brown, L. Moran, D. C. Roopenian and P. J. Baker (2004). "Quantitative gene expression profiling implicates genes for susceptibility and resistance to alveolar bone loss." Infect Immun 72(8): 44714479 . 
67. Hasebe, A., A. Yoshimura, T. Into, H. Kataoka, S. Tanaka, S. Arakawa, H. Ishikura, D. T. Golenbock, T. Sugaya, N. Tsuchida, M. Kawanami, Y. Hara and K. Shibata (2004). "Biological activities of Bacteroides forsythus lipoproteins and their possible pathological roles in periodontal disease." Infect Immun 72(3): 1318-1325.

68. Hayden, M. S. and S. Ghosh (2004). "Signaling to NF-kappaB." Genes Dev 18(18): 2195-2224.

69. Herath, T. D., R. P. Darveau, C. J. Seneviratne, C. Y. Wang, Y. Wang and L. Jin (2013). "Tetra- and penta-acylated lipid A structures of Porphyromonas gingivalis LPS differentially activate TLR4-mediated NF-kappaB signal transduction cascade and immuno-inflammatory response in human gingival fibroblasts." PLoS One 8(3): e58496.

70. Hirasawa, M., K. Takada, M. Makimura and S. Otake (2002). "Improvement of periodontal status by green tea catechin using a local delivery system: a clinical pilot study." J Periodontal Res 37(6): 433-438.

71. Holt, S. C., L. Kesavalu, S. Walker and C. A. Genco (1999). "Virulence factors of Porphyromonas gingivalis." Periodontol 2000 20: 168-238.

72. Holtrop, M. E. and G. J. King (1977). "The ultrastructure of the osteoclast and its functional implications." Clin Orthop Relat Res(123): 177-196.

73. Houde, V., D. Grenier and F. Chandad (2006). "Protective effects of grape seed proanthocyanidins against oxidative stress induced by lipopolysaccharides of periodontopathogens." J Periodontol 77(8): 1371-1379. 
74. How, K. Y., K. P. Song and K. G. Chan (2016). "Porphyromonas gingivalis: An Overview of Periodontopathic Pathogen below the Gum Line." Frontiers in microbiology 7: 53-53.

75. Huang, G. T., H. B. Zhang, H. N. Dang and S. K. Haake (2004). "Differential regulation of cytokine genes in gingival epithelial cells challenged by Fusobacterium nucleatum and Porphyromonas gingivalis." Microb Pathog 37(6): 303-312.

76. Irwin, C. R. and T. T. Myrillas (1998). "The role of IL-6 in the pathogenesis of periodontal disease." Oral Dis 4(1): 43-47.

77. Ishimi, Y., C. Miyaura, C. H. Jin, T. Akatsu, E. Abe, Y. Nakamura, A. Yamaguchi, S. Yoshiki, T. Matsuda, T. Hirano and et al. (1990). "IL-6 is produced by osteoblasts and induces bone resorption." J Immunol 145(10): 32973303.

78. Iyer, S. S. and G. Cheng (2012). "Role of interleukin 10 transcriptional regulation in inflammation and autoimmune disease." Critical reviews in immunology 32(1): 23-63.

79. Jacome-Galarza, C. E., S.-K. Lee, J. A. Lorenzo and H. LeonardoAguila (2013). "Identification, characterization and isolation of a common progenitor for osteoclasts, macrophages and dendritic cells from murine bone marrow and periphery." Journal of bone and mineral research : the official journal of the American Society for Bone and Mineral Research 28(5): 1203-1213.

80. Jacome-Galarza, C. E., S. K. Lee, J. A. Lorenzo and H. L. Aguila (2013).

"Identification, characterization, and isolation of a common progenitor for 
osteoclasts, macrophages, and dendritic cells from murine bone marrow and periphery." J Bone Miner Res 28(5): 1203-1213.

81. Jandinski, J. J., P. Stashenko, L. S. Feder, C. C. Leung, W. J. Peros, J. E. Rynar and M. J. Deasy (1991). "Localization of interleukin-1 beta in human periodontal tissue." J Periodontol 62(1): 36-43.

82. Jin, W. and C. Dong (2013). "IL-17 cytokines in immunity and inflammation." Emerging microbes \& infections 2(9): e60-e60.

83. Kamitani, Y., K. Maki, I. Tofani, Y. Nishikawa, K. Tsukamoto and M. Kimura (2004). "Effects of grape seed proanthocyanidins extract on mandibles in developing rats." 10(1): 27-31.

84. Karin, M. and A. Lin (2002). "NF-kappaB at the crossroads of life and death." Nat Immunol 3(3): 221-227.

85. Kassebaum, N. J., A. G. C. Smith, E. Bernabé, T. D. Fleming, A. E. Reynolds, T. Vos, C. J. L. Murray and W. Marcenes (2017). "Global, Regional, and National Prevalence, Incidence, and Disability-Adjusted Life Years for Oral Conditions for 195 Countries, 1990-2015: A Systematic Analysis for the Global Burden of Diseases, Injuries, and Risk Factors." Journal of Dental Research 96(4): 380-387.

86. Kaur, G., V. Grover, N. Bhaskar, R. K. Kaur and A. Jain (2018). "Periodontal Infectogenomics." Inflammation and regeneration 38: 8-8.

87. Kempuraj, D., B. Madhappan, S. Christodoulou, W. Boucher, J. Cao, N. Papadopoulou, C. L. Cetrulo and T. C. Theoharides (2005). "Flavonols inhibit proinflammatory mediator release, intracellular calcium ion levels and protein 
kinase $\mathrm{C}$ theta phosphorylation in human mast cells." British journal of pharmacology 145(7): 934-944.

88. Khader, Y. S., A. S. Dauod, S. S. El-Qaderi, A. Alkafajei and W. Q. Batayha (2006). "Periodontal status of diabetics compared with nondiabetics: a metaanalysis." J Diabetes Complications 20(1): 59-68.

89. Kim, S. J., M. S. Ha, E. Y. Choi, J. I. Choi and I. S. Choi (2004). "Prevotella intermedia lipopolysaccharide stimulates release of nitric oxide by inducing expression of inducible nitric oxide synthase." J Periodontal Res 39(6): 424-431.

90. Kinane, D. F., P. G. Stathopoulou and P. N. Papapanou (2017). "Periodontal diseases." Nat Rev Dis Primers 3: 17038.

91. Kinane, D. F., F. P. Winstanley, E. Adonogianaki and N. A. Moughal (1992). "Bioassay of interleukin 1 (IL-1) in human gingival crevicular fluid during experimental gingivitis." Arch Oral Biol 37(2): 153-156.

92. Kishimoto, T. (1989). "The biology of interleukin-6." Blood 74(1): 1-10.

93. Klausen, B. (1991). "Microbiological and immunological aspects of experimental periodontal disease in rats: a review article." J Periodontol 62(1): 59-73.

94. Kobayashi-Sakamoto, M., K. Hirose, E. Isogai and I. Chiba (2004). "NF-kappaBdependent induction of osteoprotegerin by Porphyromonas gingivalis in endothelial cells." Biochem Biophys Res Commun 315(1): 107-112.

95. Koide, M., S. Suda, S. Saitoh, Y. Ofuji, T. Suzuki, H. Yoshie, M. Takai, Y. Ono, Y. Taniguchi and K. Hara (1995). "In vivo administration of IL-1 beta accelerates silk ligature-induced alveolar bone resorption in rats." J Oral Pathol Med 24(9): $420-434$. 
96. Kothari, M., R. S. Pillai, S. F. Kothari, R. Spin-Neto, A. Kumar and J. F. Nielsen (2017). "Oral health status in patients with acquired brain injury: a systematic review." Oral Surg Oral Med Oral Pathol Oral Radiol 123(2): 205-219.e207.

97. Kuboniwa, M., J. R. Houser, E. L. Hendrickson, Q. Wang, S. A. Alghamdi, A. Sakanaka, D. P. Miller, J. A. Hutcherson, T. Wang, D. A. C. Beck, M. Whiteley, A. Amano, H. Wang, E. M. Marcotte, M. Hackett and R. J. Lamont (2017). "Metabolic crosstalk regulates Porphyromonas gingivalis colonization and virulence during oral polymicrobial infection." Nat Microbiol 2(11): 1493-1499.

98. Labow, M., D. Shuster, M. Zetterstrom, P. Nunes, R. Terry, E. B. Cullinan, T. Bartfai, C. Solorzano, L. L. Moldawer, R. Chizzonite and K. W. McIntyre (1997). "Absence of IL-1 signaling and reduced inflammatory response in IL-1 type I receptor-deficient mice." J Immunol 159(5): 2452-2461.

99. Labrecque, J., C. Bodet, F. Chandad and D. Grenier (2006). "Effects of a highmolecular-weight cranberry fraction on growth, biofilm formation and adherence of Porphyromonas gingivalis." J Antimicrob Chemother 58(2): 439-443.

100. Lawrence, T. (2009). "The nuclear factor NF-kappaB pathway in inflammation." Cold Spring Harb Perspect Biol 1(6): a001651.

101. Lee, J. W., Y. I. Kim, Y. Kim, M. Choi, S. Min, Y. H. Joo, S. V. Yim and N. Chung (2017). "Grape seed proanthocyanidin inhibits inflammatory responses in hepatic stellate cells by modulating the MAPK, Akt and NF-kappaB signaling pathways." Int J Mol Med 40(1): 226-234. 
102. Li, C. H. and S. Amar (2007). "Morphometric, histomorphometric, and microcomputed tomographic analysis of periodontal inflammatory lesions in a murine model." J Periodontol 78(6): 1120-1128.

103. Liang, S., K. B. Hosur, H. Domon and G. Hajishengallis (2010).

"Periodontal inflammation and bone loss in aged mice." Journal of periodontal research 45(4): 574-578.

104. Lifshitz, V. and D. Frenkel (2013). Chapter 225 - TGF- $\beta$. $\underline{\text { Handbook of }}$ Biologically Active Peptides (Second Edition). A. J. Kastin. Boston, Academic Press: $1647-1653$.

105. Liu, W. and X. Zhang (2015). "Receptor activator of nuclear factorkappaB ligand (RANKL)/RANK/osteoprotegerin system in bone and other tissues (review)." Mol Med Rep 11(5): 3212-3218.

106. Lodhi, M. A. and B. I. Reisch (1995). "Nuclear DNA content of Vitis species, cultivars, and other genera of the Vitaceae." Theor Appl Genet 90(1): 1116.

107. Maeda, K., H. Nagata, M. Ojima and A. Amano (2015). "Proteomic and transcriptional analysis of interaction between oral microbiota Porphyromonas gingivalis and Streptococcus oralis." J Proteome Res 14(1): 82-94.

108. Middleton, E., Jr., C. Kandaswami and T. C. Theoharides (2000). "The effects of plant flavonoids on mammalian cells: implications for inflammation, heart disease, and cancer." Pharmacol Rev 52(4): 673-751.

109. Miossec, P., T. Korn and V. K. Kuchroo (2009). "Interleukin-17 and type 17 helper T cells." N Engl J Med 361(9): 888-898. 
110. Mogensen, T. H. (2009). "Pathogen recognition and inflammatory signaling in innate immune defenses." Clin Microbiol Rev 22(2): 240-273, Table of Contents.

111. Monagas, M., C. Gomez-Cordoves, B. Bartolome, O. Laureano and J. M. Ricardo da Silva (2003). "Monomeric, oligomeric, and polymeric flavan-3-ol composition of wines and grapes from Vitis vinifera L. Cv. Graciano, Tempranillo, and Cabernet Sauvignon." J Agric Food Chem 51(22): 6475-6481.

112. Murthy, V. H. (2016). "Oral Health in America, 2000 to Present: Progress made, but Challenges Remain." Public health reports (Washington, D.C. : 1974) 131(2): 224-225.

113. Myint, P. K., A. A. Welch, S. A. Bingham, P. G. Surtees, N. W. Wainwright, R. N. Luben, N. J. Wareham, R. D. Smith, I. M. Harvey, N. E. Day and K. T. Khaw (2007). "Fruit and vegetable consumption and self-reported functional health in men and women in the European Prospective Investigation into Cancer-Norfolk (EPIC-Norfolk): a population-based cross-sectional study." Public Health Nutr 10(1): 34-41.

114. Mysak, J., S. Podzimek, P. Sommerova, Y. Lyuya-Mi, J. Bartova, T. Janatova, J. Prochazkova and J. Duskova (2014). "Porphyromonas gingivalis: major periodontopathic pathogen overview." J Immunol Res 2014: 476068. 115. Nagy, V. and J. M. Penninger (2015). "The RANKL-RANK Story." Gerontology 61(6): 534-542.

116. Nakagawa, T. and T. Yokozawa (2002). "Direct scavenging of nitric oxide and superoxide by green tea." Food Chem Toxicol 40(12): 1745-1750. 
117. Nanri, H., Y. Yamada, A. Itoi, E. Yamagata, Y. Watanabe, T. Yoshida, M. Miyake, H. Date, K. Ishikawa-Takata, M. Yoshida, T. Kikutani and M. Kimura (2017). "Frequency of Fruit and Vegetable Consumption and the Oral HealthRelated Quality of Life among Japanese Elderly: A Cross-Sectional Study from the Kyoto-Kameoka Study." Nutrients 9(12): 1362.

118. Narita, N., Y. Kobayashi, H. Nakamura, K. Maeda, A. Ishihara, T. Mizoguchi, Y. Usui, K. Aoki, M. Simizu, H. Kato, H. Ozawa, N. Udagawa, M. Endo, N. Takahashi and N. Saito (2009). "Multiwalled carbon nanotubes specifically inhibit osteoclast differentiation and function." Nano Lett 9(4): 14061413.

119. Newman, M.-A., T. Sundelin, J. T. Nielsen and G. Erbs (2013). "MAMP (microbe-associated molecular pattern) triggered immunity in plants." Frontiers in plant science 4: 139-139.

120. Nichols, T. C., T. H. Fischer, E. N. Deliargyris and A. S. Baldwin, Jr. (2001). "Role of nuclear factor-kappa B (NF-kappa B) in inflammation, periodontitis, and atherogenesis." Ann Periodontol 6(1): 20-29.

121. O'Garra, A., F. J. Barrat, A. G. Castro, A. Vicari and C. Hawrylowicz (2008). "Strategies for use of IL-10 or its antagonists in human disease." Immunol Rev 223: 114-131.

122. Oeckinghaus, A. and S. Ghosh (2009). "The NF-kappaB family of transcription factors and its regulation." Cold Spring Harb Perspect Biol 1(4): a000034. 
123. Oeckinghaus, A., M. S. Hayden and S. Ghosh (2011). "Crosstalk in NFkappaB signaling pathways." Nat Immunol 12(8): 695-708.

124. Ogawa, T. (1993). "Chemical structure of lipid A from Porphyromonas (Bacteroides) gingivalis lipopolysaccharide." FEBS Lett 332(1-2): 197-201.

125. Okamoto, T. (2006). "NF-kappaB and rheumatic diseases." Endocr Metab Immune Disord Drug Targets 6(4): 359-372.

126. Olsen, I., J. D. Lambris and G. Hajishengallis (2017). "Porphyromonas gingivalis disturbs host-commensal homeostasis by changing complement function." Journal of Oral Microbiology 9(1): 1340085.

127. Onishi, R. M. and S. L. Gaffen (2010). "Interleukin-17 and its target genes: mechanisms of interleukin-17 function in disease." Immunology 129(3): 311-321.

128. Ouyang, W., S. Rutz, N. K. Crellin, P. A. Valdez and S. G. Hymowitz (2011). "Regulation and functions of the IL-10 family of cytokines in inflammation and disease." Annu Rev Immunol 29: 71-109.

129. Oz, H. S. and D. A. Puleo (2011). "Animal models for periodontal disease." Journal of biomedicine \& biotechnology 2011: 754857-754857.

130. Oz, H. S. and D. A. Puleo (2011). "Animal models for periodontal disease." J Biomed Biotechnol 2011: 754857.

131. Özden, F. O., E. E. Sakallioğlu, U. Sakallioğlu, B. Ayas and Z. Erişgin (2017). "Effects of grape seed extract on periodontal disease: an experimental study in rats." Journal of applied oral science : revista FOB 25(2): 121-129. 
132. Pacios, S., W. Xiao, M. Mattos, J. Lim, R. S. Tarapore, S. Alsadun, B. Yu, C.-Y. Wang and D. T. Graves (2015). "Osteoblast Lineage Cells Play an Essential Role in Periodontal Bone Loss Through Activation of Nuclear Factor-Kappa B." Scientific reports 5: 16694-16694.

133. Pahl, H. L. (1999). "Activators and target genes of Rel/NF-kappaB transcription factors." Oncogene 18(49): 6853-6866.

134. Pahl, H. L. (1999). "Activators and target genes of Rel/NF-кB transcription factors." Oncogene 18: 6853.

135. Palaska, I., E. Papathanasiou and T. C. Theoharides (2013). "Use of polyphenols in periodontal inflammation." European Journal of Pharmacology 720(1): 77-83.

136. Park, B. S. and J.-O. Lee (2013). "Recognition of lipopolysaccharide pattern by TLR4 complexes." Experimental \& Molecular Medicine 45(12): e66. 137. Park, J.-S., M.-K. Park, H.-J. Oh, Y.-J. Woo, M.-A. Lim, J.-H. Lee, J. H. Ju, Y. O. Jung, Z. H. Lee, S.-H. Park, H.-Y. Kim, M.-L. Cho and J.-K. Min (2012). "Grape-Seed Proanthocyanidin Extract as Suppressors of Bone Destruction in Inflammatory Autoimmune Arthritis." PLoS ONE 7(12): e51377. 138. Park, K. J., V. Krishnan, B. W. O'Malley, Y. Yamamoto and R. B. Gaynor (2005). "Formation of an IKKalpha-dependent transcription complex is required for estrogen receptor-mediated gene activation." Mol Cell 18(1): 71-82.

139. Petersen, P. E., D. Bourgeois, H. Ogawa, S. Estupinan-Day and C. Ndiaye (2005). "The global burden of oral diseases and risks to oral health." Bull World Health Organ 83(9): 661-669. 
140. Pezzuto, J. (2008). "Grapes and Human Health: A Perspective." Journal of Agricultural and Food Chemistry: 6777-6784.

141. Raetz, C. R. and C. Whitfield (2002). "Lipopolysaccharide endotoxins." Annu Rev Biochem 71: 635-700.

142. Rafiei, M., F. Kiani, F. Sayehmiri, K. Sayehmiri, A. Sheikhi and M. Zamanian Azodi (2017). "Study of Porphyromonas gingivalis in periodontal diseases: A systematic review and meta-analysis." Medical journal of the Islamic Republic of Iran 31: 62-62.

143. Ross, J. A. and C. M. Kasum (2002). "Dietary flavonoids: bioavailability, metabolic effects, and safety." Annu Rev Nutr 22: 19-34.

144. Ross, J. S., N. E. Stagliano, M. J. Donovan, R. E. Breitbart and G. S. Ginsburg (2001). "Atherosclerosis: a cancer of the blood vessels?" Am J Clin Pathol 116 Suppl: S97-107.

145. Sen, R. and D. Baltimore (1986). "Inducibility of kappa immunoglobulin enhancer-binding protein Nf-kappa B by a posttranslational mechanism." Cell 47(6): 921-928.

146. Senthil Kumar, K. J. and S. Y. Wang (2009). "Lucidone inhibits iNOS and COX-2 expression in LPS-induced RAW 264.7 murine macrophage cells via NFkappaB and MAPKs signaling pathways." Planta Med 75(5): 494-500.

147. Shalit, I., D. Halperin, D. Haite, A. Levitov, J. Romano, N. Osherov and I. Fabian (2006). "Anti-inflammatory effects of moxifloxacin on IL-8, IL-1beta and TNF-alpha secretion and NFkappaB and MAP-kinase activation in human 
monocytes stimulated with Aspergillus fumigatus." J Antimicrob Chemother 57(2): 230-235.

148. Singh, M., S. Tyagi, K. Bhui, S. Prasad and Y. Shukla (2010). "Regulation of cell growth through cell cycle arrest and apoptosis in HPV 16 positive human cervical cancer cells by tea polyphenols." Invest New Drugs 28(3): 216-224.

149. Skaleric, U., B. Kramar, M. Petelin, Z. Pavlica and S. M. Wahl (1997). "Changes in TGF-beta 1 levels in gingiva, crevicular fluid and serum associated with periodontal inflammation in humans and dogs." Eur J Oral Sci 105(2): 136142.

150. Socransky, S. S., A. D. Haffajee, M. A. Cugini, C. Smith and R. L. Kent, Jr. (1998). "Microbial complexes in subgingival plaque." J Clin Periodontol 25(2): 134-144.

151. St-Denis, A., F. Chano, P. Tremblay, Y. St-Pierre and A. Descoteaux (1998). "Protein kinase C-alpha modulates lipopolysaccharide-induced functions in a murine macrophage cell line." J Biol Chem 273(49): 32787-32792.

152. Takahashi, K., T. Azuma, H. Motohira, D. F. Kinane and S. Kitetsu (2005). "The potential role of interleukin-17 in the immunopathology of periodontal disease." J Clin Periodontol 32(4): 369-374.

153. Takayanagi, H., H. Iizuka, T. Juji, T. Nakagawa, A. Yamamoto, T. Miyazaki, Y. Koshihara, H. Oda, K. Nakamura and S. Tanaka (2000). "Involvement of receptor activator of nuclear factor kappaB ligand/osteoclast differentiation factor in osteoclastogenesis from synoviocytes in rheumatoid arthritis." Arthritis Rheum 43(2): 259-269. 
154. Tanabe, S., C. Bodet and D. Grenier (2008). "Treponema denticola lipooligosaccharide activates gingival fibroblasts and upregulates inflammatory mediator production." J Cell Physiol 216(3): 727-731.

155. Tanaka, Y., S. Nakayamada and Y. Okada (2005). "Osteoblasts and osteoclasts in bone remodeling and inflammation." Curr Drug Targets Inflamm Allergy 4(3): 325-328.

156. Tergaonkar, V. (2006). "NFkappaB pathway: a good signaling paradigm and therapeutic target." Int J Biochem Cell Biol 38(10): 1647-1653.

157. Tiranathanagul, S., T. Yongchaitrakul, K. Pattamapun and P. Pavasant (2004). "Actinobacillus actinomycetemcomitans lipopolysaccharide activates matrix metalloproteinase-2 and increases receptor activator of nuclear factorkappaB ligand expression in human periodontal ligament cells." J Periodontol 75(12): 1647-1654.

158. Toker, H., H. Balci Yuce, A. Lektemur Alpan, F. Gevrek and M. Elmastas (2018). "Morphometric and histopathological evaluation of the effect of grape seed proanthocyanidin on alveolar bone loss in experimental diabetes and periodontitis." J Periodontal Res 53(3): 478-486.

159. Tonetti, M. S., H. Greenwell and K. S. Kornman (2018). "Staging and grading of periodontitis: Framework and proposal of a new classification and case definition." 89(S1): S159-S172.

160. Torregrosa, L., A. Bigard, A. Doligez, D. Lecourieux, M. Rienth, N. Luchaire, P. Pieri, R. Chatbanyong, R. Shahood, M. Farnos, C. Roux, A. Adiveze, J. Pillet, Y. Sire, E. Zumstein, M. Veyret, L. Le Cunff, F. Lecourieux Ouaked, N. 
Saurin and C. Romieu (2017). Developmental, molecular and genetic studies on grapevine response to temperature open breeding strategies for adaptation to warming.

161. Valen, G., Z. Q. Yan and G. K. Hansson (2001). "Nuclear factor kappa-B and the heart." J Am Coll Cardiol 38(2): 307-314.

162. Walter, C., J. Zahlten, B. Schmeck, C. Schaudinn, S. Hippenstiel, E. Frisch, A. C. Hocke, N. Pischon, H. K. Kuramitsu, J. P. Bernimoulin, N. Suttorp and M. Krull (2004). "Porphyromonas gingivalis strain-dependent activation of human endothelial cells." Infect Immun 72(10): 5910-5918.

163. Wang, P. L., M. Oido-Mori, T. Fujii, Y. Kowashi, M. Kikuchi, Y. Suetsugu, J. Tanaka, Y. Azuma, M. Shinohara and K. Ohura (2001). "Heterogeneous expression of Toll-like receptor 4 and downregulation of Tolllike receptor 4 expression on human gingival fibroblasts by Porphyromonas gingivalis lipopolysaccharide." Biochem Biophys Res Commun 288(4): 863-867.

164. Wang, X. and P. J. Quinn (2010). "Endotoxins: lipopolysaccharides of gram-negative bacteria." Subcell Biochem 53: 3-25.

165. Yadav, D., A. Kumar, P. Kumar and D. Mishra (2015). "Antimicrobial properties of black grape (Vitis vinifera L.) peel extracts against antibioticresistant pathogenic bacteria and toxin producing molds." Indian journal of pharmacology 47(6): 663-667.

166. Yamaguchi, M., M. N. Weitzmann and T. Murata (2012). "Exogenous regucalcin stimulates osteoclastogenesis and suppresses osteoblastogenesis through NF-kappaB activation." Mol Cell Biochem 359(1-2): 193-203. 
167. Yang, L., D. Xian, X. Xiong, R. Lai, J. Song and J. Zhong (2018).

"Proanthocyanidins against Oxidative Stress: From Molecular Mechanisms to Clinical Applications." BioMed Research International 2018: 8584136.

168. Zhang, G. and S. Ghosh (2001). "Toll-like receptor-mediated NF-kappaB activation: a phylogenetically conserved paradigm in innate immunity." $\underline{\mathrm{J} \text { Clin }}$ Invest 107(1): 13-19.

169. Zhang, J.-M. and J. An (2007). "Cytokines, Inflammation and Pain." International anesthesiology clinics 45(2): 27-37.

170. Zhang, Q., B. Chen, F. Yan, J. Guo, X. Zhu, S. Ma and W. Yang (2014).

"Interleukin-10 inhibits bone resorption: a potential therapeutic strategy in periodontitis and other bone loss diseases." BioMed research international 2014: 284836-284836.

171. Zhang, W., E. B. Swearingen, J. Ju, T. Rigney and G. D. Tribble (2010). "Porphyromonas gingivalis invades osteoblasts and inhibits bone formation." Microbes Infect 12(11): 838-845.

172. Zhang, Y. H., A. Heulsmann, M. M. Tondravi, A. Mukherjee and Y. AbuAmer (2001). "Tumor necrosis factor-alpha (TNF) stimulates RANKL-induced osteoclastogenesis via coupling of TNF type 1 receptor and RANK signaling pathways." J Biol Chem 276(1): 563-568.

173. Zhou, W., L. Su, X. Duan, X. Chen, A. Hays, S. Upadhyayula, J. Shivde, H. Wang, Y. Li, D. Huang and S. Liang (2018). "MicroRNA-21 down-regulates inflammation and inhibits periodontitis." Mol Immunol 101: 608-614. 


\section{CURRICULUM VITAE}

NAME: Juili Subodh Shivde

ADDRESS: Dept. of Oral Immunology and Infectious Diseases

University of Louisville School of Dentistry

501 South Preston Louisville, KY 40202

EDUCATION \& TRAINING

Bachelor of Dental Surgery

Maharashtra University of Health Sciences, India

2010-2015

Master of Science in Oral Biology

University of Louisville School of Dentistry, Louisville, KY

2017-2018

PROFESSIONAL SOCIETIES

Indian Dental Association $\quad 2010$ - Ongoing

American Red Cross 2017 - Ongoing

PRESENTATIONS

Poster presentation: P. stomatis Stimulates Toll-like Receptor Signaling to Activate Human Neutrophils

Research! Louisville, Louisville, KY September 2017

Poster presentation: Effect of Grape Components on Periodontal Disease

Research! Louisville, Louisville, KY October 2018 